\title{
Designing Decentralized Markets for Distribution System Flexibility
}

\author{
Thomas Morstyn, Member, IEEE, Alexander Teytelboym, and Malcolm D. McCulloch, Senior Member, IEEE
}

\begin{abstract}
This paper introduces a decentralized market design, which allows a distribution system operator to manage local demand constraints by obtaining flexibility from competing aggregators, which must in-turn incentivize prosumers to provide this flexibility. The novel networked market structure accounts for distribution system operator-to-aggregator and aggregatorto-prosumer ICT infrastructure and contractual arrangements, which may limit which participants can negotiate transactions with one another. The proposed flexibility market is opt-in for prosumers, which continue to obtain energy within the existing retail electricity market. At the same time, it is underpinned by bilateral energy transactions, and could be integrated into future peer-to-peer electricity markets. Through the market, the distribution system operator, aggregators and prosumers reach agreement on a stable outcome - a set of individually beneficial transactions no group wishes to mutually deviate from. Market outcomes also satisfy Pareto efficiency, meaning that it is not possible to make a participant better off, without making another worse off.
\end{abstract}

Index Terms-Blockchain, demand-side response, distribution network, distribution system operator, electricity markets, game theory, market design, matching markets, peer-to-peer, prosumer, smart grid, transactive energy.

\section{NOMENCLATURE}

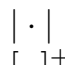

$[\cdot]^{+}$

$\alpha_{t}$

$\beta$

$\gamma_{i}$

$\Delta p$

$\kappa(\cdot)$

$\tau(\cdot)$

$\Phi$

$\Psi$

$\Omega$

$\omega$

$\mathcal{A}$

$B$

$a(\cdot)$

$b(\cdot)$

$C_{i}(\cdot)$

$c_{1 j}$

\section{Number of elements of a set}

$\max \{\cdot, 0\}$

Difference between $p_{i t}^{b}$ and $p_{i t}^{s}$

Element of $\{0,1\}$

Agent $i$ 's utility coefficient for early charging

Price adjustment increment

Selected contracts of an arrangement

Underlying trades for a set of contracts

Set of over-demanded trades

Subset of trades maximizing an agent's utility

Set of trades

A trade

Set of agents

Blocking set of contracts

Set of agents associated with a set of contracts

Buyer of a trade or contract

Agent $i$ 's choice correspondence

Aggregator $j$ 's transaction cost coefficient

This work is supported by the Engineering and Physical Sciences Research Council (award references EP/S000887/1 and EP/N03466X/1) and the Oxford Martin Programme on Integrating Renewable Energy.

T. Morstyn and M. D. McCulloch are with the Department of Engineering Science at the University of Oxford, Oxford OX1 2JD, United Kingdom (email: thomas.morstyn@eng.ox.ac.uk, malcolm.mcculloch@eng.ox.ac.uk).

A. Teytelboym is with the Department of Economics, University of Oxford, Manor Road, Oxford, OX1 3UQ, United Kingdom (email: alexander.teytelboym@economics.ox.ac.uk).

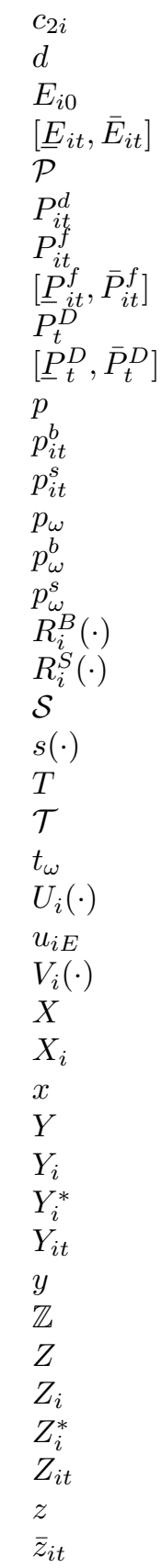

Prosumer $i$ 's battery cost coefficient

The index of the DSO agent

Agent $i$ 's initial stored energy

Agent $i$ 's energy storage limits for time $t$

Set of prosumer agents

Agent $i$ 's net inflexible demand for time $t$

Agent $i$ 's planned retail flexible demand for $t$

Agent $i$ 's flexible power limits for time $t$

Pre-flexibility market retail demand for time $t$

Distribution network demand limits for time $t$

Vector of contract prices

Agent $i$ 's retail energy price for time $t$

Agent $i$ 's retail feed-in rate for time $t$

Price (or prices) of a trade (or set of trades)

Buyer price of trade $\omega$

Seller price of trade $\omega$

Agent $i$ 's rejected upstream contracts

Agent $i$ 's rejected downstream contracts

Set of aggregator agents

Seller of a trade or contract

Number of time intervals

Set of time intervals

Time interval of trade $\omega$

Agent $i$ 's utility function

Agent $i$ 's utility coefficient for stored energy

Agent $i$ 's indirect utility function

Set of available contracts

Agent $i$ 's contracts

A contract

Set of available upstream contracts

Agent $i$ 's available upstream contracts

Agent $i$ 's selected upstream contracts

Agent $i$ 's upstream contracts for time $t$

An upstream contract

Set of integers

Set of available downstream contracts

Agent $i$ 's available downstream contracts

Agent $i$ 's selected downstream contracts

Agent $i$ 's downstream contracts for time $t$

A downstream contract

Agent $i$ 's net flexible demand for time $t$

\section{INTRODUCTION}

$\mathbf{T}$ HIS paper investigates how decentralized flexibility markets could be used to incentivize consumers with smallscale energy resources, such as electric vehicles and home batteries, to help manage distribution network demand considering existing retail electricity market arrangements. 
Consumer-level flexible energy technologies are increasingly being incorporated into distribution networks [1]. When combined with consumer-level communications and processing, these resources allow previously passive consumers to become 'prosumers' - consumers who proactively manage their consumption, production and storage of energy [2].

Even in countries with liberalized electricity markets, prosumers cannot directly participate in wholesale energy trading due to their small size [3]. Instead, they are served in the retail electricity market by a supplier that meters their individual energy demand. This incentivizes prosumers to optimize their demand 'behind-the-meter', but does not integrate their flexibility into the overall operation of the power system [4].

Previously, distribution system operators (DSOs) have managed local demand through long-term physical network reinforcement [5]. However, without active coordination, the introduction of distributed renewables and the electrification of transport and heat are expected to lead to increasingly costly distribution networks, with more severe demand variability requiring investment in rarely used infrastructure [6].

Optimization approaches have been studied for coordinating flexible energy resources in distribution networks and microgrids [7]-[10]. However, these strategies require a single DSO or aggregator that can control all of the flexible energy resources. These strategies do not address how prosumers can be incentivized to provide flexibility, and do not consider prosumers who may be willing to provide some flexibility, but may be unwilling to cede full control [11].

Transactive energy mechanisms that instead incentivize coordination are a promising approach for integrating the individual preferences and resource characteristics of prosumers [12]. Time-of-use energy prices, as well as unidirectional price signals rewarding demand response, have been proposed to shift flexible loads to periods with low expected demand [13], [14]. A limitation is that new demand peaks can be created if all prosumers follow the same signals [15]. Flexible resources need to be coordinated in time, but also need to be coordinated relative to one another.

Distributed optimization based on dual price variable adjustments can be considered analogous to an auction mechanism [16]. Local energy market designs based on distributed price-based optimization strategies are presented in [17]-[20]. However, these strategies require cooperation to achieve convergence, since participants must implement correctly chosen penalty terms when solving local sub-problems, rather than making utility maximizing decisions. Local energy market designs have also been proposed based on double-sided auctions [21]-[24], mean-field game theory [25]-[27] and Stackelberg leader-follower games [28]-[31]. Field trials of local energy market designs have also been carried out in several countries [32], [33]. However, barriers remain for designs which would replace existing retail electricity markets, particularly if they expose small-scale consumers without flexible resources to wholesale energy price fluctuations [34].

An alternative approach is to retain existing retail market arrangements, but to allow DSOs to organize additional local flexibility markets to help manage constraints. Market designs focused on incentivizing distribution system flexibility within existing market arrangements are presented in [35]-[38]. The designs in [35]-[37] focus on the negotiations between a DSO and aggregators, but do not consider negotiations between aggregators and the prosumers who will ultimately provide the flexibility. In [38], a bi-level optimization approach is presented, where a DSO sets flexibility prices and volumes based on full information about the preferences and resource characteristics of its supply chain of aggregators and prosumers. However, if a DSO has limited information, it will not be able to use this approach to obtain the flexibility it requires.

Recently, new designs for peer-to-peer (P2P) energy trading have been proposed for integrating prosumer flexibility into power system operations [39]-[41]. Market designs allowing prosumers to engage directly in bilateral energy transactions have advantages for prosumers with preferences related to autonomy, trust and privacy. If P2P energy trading platforms become widespread, new mechanisms will be needed allowing DSOs to engage and negotiate with aggregators and prosumers to obtain flexibility [42].

In [43], it is recognized that within existing electricity market arrangements a limiting factor for establishing new markets for distribution system flexibility is a lack of liquidity, compromising competition. This motivates the need for new market designs that can integrate flexibility from multiple competing aggregators and prosumers with diverse energy resources and preferences.

This paper introduces a decentralized market design, which allows a DSO to manage local demand constraints by obtaining flexibility from competing aggregators, which must in-turn incentivize prosumers to provide this flexibility. The novel networked market structure accounts for DSO-to-aggregator and aggregator-to-prosumer ICT infrastructure and contractual arrangements, which may limit which participants can negotiate transactions with one another. In addition, the market fulfills the following design requirements:

- The flexibility market should be opt-in for prosumers, and should account for their incentives within the retail electricity market.

- Even when acting autonomously and making individually rational decisions, the DSO, aggregators and prosumers should reach agreement on a stable outcome - a set of individually beneficial transactions no group wishes to mutually deviate from.

- Market outcomes should satisfy Pareto efficiency, meaning that it should not be possible to make one participant better off without making another worse off.

This paper extends the authors' previous work in [39], which introduced networked matching market theory for P2P energy market design. Here, this framework is extended from prosumer-to-prosumer energy trading, to flexibility trading between prosumers, aggregators and a DSO. In addition, the framework is extended from single time interval trading, to multi time interval trading. This allows time-dependent prosumer preferences to be incorporated; for example electric vehicle owners that prefer charging sooner rather than later, and prosumers that face retail energy prices that are time-ofuse based. 


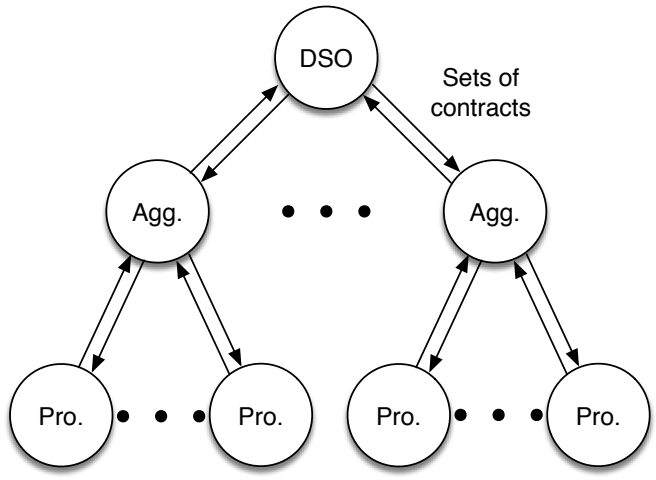

Fig. 1. A trading network for distribution system flexibility between a DSO, aggregators and local prosumers. Aggregators act as intermediaries between a DSO and subscribed prosumers. The agents negotiate a set of flexibility contracts, each representing an agreed reduction in demand during a particular time interval.

The rest of this paper is organized as follows. Section II presents the principle of operation for the proposed market design. Section III describes the DSO, aggregator and prosumer preferences. Section IV sets out conditions establishing the existence of a stable market outcome. Section V describes the price-negotiation mechanism. In Section VI, simulation case studies are presented demonstrating the operation of the proposed market design. Section VII concludes the paper. In the Appendix, it is shown that the agent preferences satisfy the conditions for a stable market outcome to exist.

\section{Decentralized Flexibility Market Design}

The proposed flexibility market works alongside existing retail electricity market arrangements in a distribution network. It is assumed that the distribution network has a number of prosumers - consumers with flexible energy resources, and equipment for automated resource scheduling based on user settings, such as a building or home energy management system [44]. Each prosumer has a retail supplier, which meters their individual net energy use (e.g. during each 30 minute interval of the day). For each interval, each prosumer is charged for their net energy use, at prices which may be timeof-use dependent, and paid for their net exported energy [45].

It is assumed that the DSO is responsible for ensuring the total demand in the distribution network does not exceed a maximum limit. The proposed flexibility market design allows the DSO to incentivize demand flexibility from local prosumers to achieve this. ICT infrastructure and contractual agreements may be needed to facilitate the procurement of flexibility. Therefore, rather than requiring the DSO to negotiate directly with each prosumer, the proposed flexibility market is designed based on a networked structure, with the DSO able to negotiate with intermediary aggregators, and each aggregator in-turn able to negotiate with certain prosumers. Direct prosumer-to-DSO trading can also be incorporated if aggregators are not required. Throughout the paper, the DSO, prosumers and aggregators participating in the market are generically referred to as agents.

The DSO organizes a flexibility market if it predicts the distribution network demand limits could be violated. Prior to entering the flexibility market, each prosumer first plans a demand profile for their flexible energy resources, considering their costs and preferences in the retail market, using their local energy management systems.

The flexibility market is made up of a network of potential flexibility contracts, with multiple contracts connecting each pair of agents that are able to trade with one another. Fig. 1 shows a high-level diagram of a trading network for distribution system flexibility. Each flexibility contract specifies a price the seller will receive from the buyer for reducing demand during a particular retail market metering interval. Each contract specifies the same energy quantity of demand reduction, but an agent may accept multiple contracts for each time interval. The contracts discretize the prosumers' energy flexibility (in terms of energy and time), and allow each discrete unit to be individually priced. Multi-interval trading is important, since prosumers may have storage systems with finite energy capacity. In this case, their willingness to accept a contract specifying a price for a unit of demand reduction during a particular interval will depend on the price and availability of contracts at other time intervals.

The agents reach mutual agreement on a set of agreed contracts and contract prices through an iterative price-negotiation mechanism. At each step of the market, agents select their favorite bundle of available upstream and downstream contracts, and over-demanded contracts have their prices increased. The process continues until no price changes occur during an iteration.

This paper focuses on how a DSO can negotiate to obtain particular amounts of demand shifting at particular times, once other methods have been used to predict the amount of shifting that is required. Forecasting methods for distribution network demand are presented in [46], [47]. Only day-ahead trading is considered, but additional trading closer to realtime could be added, allowing agents to renegotiate based on updated demand predictions. In this case, prosumer-toprosumer transactions could be included, allowing prosumers to negotiate with peers to fulfil their previously negotiated flexibility obligations.

A 24-hour trading period is considered, given that home batteries are generally scheduled with a single charge-discharge cycle per day to flatten local PV generation, and electric vehicles are generally scheduled to recharge overnight. Longer trading periods may be desirable for flexible resources that have multi-day cycles, for example electric vehicles with different usage patterns between weekdays and weekends.

An advantage of the proposed flexibility market design is that it is integrated within existing retail electricity market arrangements. This maintains the important service which retail suppliers provide by aggregating demand variability across a large number of consumers and providing stable energy prices so that consumers are not directly exposed to wholesale energy price fluctuations.

\section{Agent Preferences}

Let $\mathcal{A}$ be the set of agents in the trading network. In the flexibility market, the agents trade flexibility contracts for a 
set of time intervals $\mathcal{T}=\{1, \ldots, T\}$. Each flexibility contract specifies a price for a flexibility trade, specifing an agreed reduction in demand during a particular time interval. Note that all trades specify the same energy quantity of demand reduction.

Let $X$ be the set of contracts between the agents. A contract $x \in X$ can be described by a tuple $\left(\omega, t_{\omega}, p_{\omega}\right)$, where $\omega \in \Omega$ is a unique trade ID, $t_{\omega}$ is the time interval of the underlying trade and $p_{\omega}$ is the price specified by the contract for the trade. The trades underlying a set of contracts $X$ are given by $\tau(X)=\left\{\omega \in \Omega \mid\left(\omega, t_{\omega}, p_{\omega}\right) \in X\right\}$.

Each contract $x$, and its underlying trade $\omega$, has a buyer $b(x)=b(\omega) \in \mathcal{A}$ and a seller $s(x)=s(\omega) \in \mathcal{A}$. The set of contracts available to agent $i$ is given by $X_{i}=\left\{x \in X_{i} \mid i \in\right.$ $b(x) \cup s(x)\}$. These can be divided into a set of upstream contracts $Y_{i}$, and a set of downstream contracts $Z_{i}$,

$$
Y_{i}=\left\{y \in X_{i} \mid b(y)=i\right\}, Z_{i}=\left\{z \in X_{i} \mid s(z)=i\right\} .
$$

These can be further divided into upstream and downstream contracts associated with each time interval $t \in \mathcal{T}$, given by,

$$
\begin{gathered}
Y_{i t}=\left\{\left(\phi, t_{\phi}, p_{\phi}\right) \in X_{i} \mid b(\phi)=i, t_{\phi}=t\right\}, \\
Z_{i t}=\left\{\left(\omega, t_{\omega}, p_{\omega}\right) \in X_{i} \mid s(\omega)=i, t_{\omega}=t\right\} .
\end{gathered}
$$

The agents associated with a set of contracts $X$ are given by $a(X)=\left\{\cup_{x \in X} b(x), s(x)\right\}$

Each agent $i \in \mathcal{A}$ has a utility function $U_{i}$ which describes its preferences over sets of contracts. The subset of contracts selected by the agent are given by its choice correspondence,

$$
C_{i}(X)=\operatorname{argmax}_{X_{i}^{\prime} \subseteq X_{i}} U_{i}\left(X_{i}^{\prime}\right)
$$

\section{A. Prosumer Preferences}

Let $\mathcal{P} \subseteq \mathcal{A}$ be the set of prosumers in the trading network. The prosumers have renewable sources, inflexible loads and flexible energy resources. The prosumers sell contracts for time intervals when they are willing to reduce their planned retail market demand. If prosumers own local flexible generation sources, they can directly sell flexibility contracts. Prosumers with energy storage systems may only be willing to sell contracts if they are able to buy contracts for other time intervals allowing them to increase their retail demand.

Prosumer $i \in \mathcal{P}$ has a net inflexible demand given by $P_{i t}^{d}, t \in \mathcal{T}$. The prosumer pays time-of-use dependent retail energy prices $p_{i t}^{b}$ for its net demand, and sells excess energy at a feed-in rate of $p_{i t}^{s}$. Unsubsidized feed-in rates are generally lower than retail energy prices, since prosumer generation is not treated as dispatchable, and is therefore considered to be less valuable than energy obtained in the wholesale market [45]. Therefore, it is assumed that $p_{i t}^{b} \geq p_{i t}^{s} \geq 0, \forall t \in \mathcal{T}$.

Prosumer $i$ 's flexible energy resource is modeled as a flexible load with energy storage capacity. Let $E_{i 0}$ be the initial stored energy and for each time interval $t \in \mathcal{T}$, let $\left[\underline{P}_{i t}^{f}, \bar{P}_{i t}^{f}\right]$ be the output power limits and let $\left[\underline{E}_{i t}, \bar{E}_{i t}\right]$ be the energy storage limits. A range of flexible loads can be modeled using these time varying constraints, for example electric vehicles which must be recharged during certain hours.

Additional costs terms can be used to model prosumer preferences associated with different types of flexible resources.
In this study, two types of flexible resources are considered, battery systems and electric vehicles. For the battery systems, a quadratic cost term $c_{i 2} \geq 0$ is included to model a degradation rate that increases with higher output power [48]. For the electric vehicles, it is assumed that in addition to only being able to charge while parked, charging sooner may be preferable to charging later. A utility coefficient $\gamma_{i} \geq 0$ is included to model the additional utility associated with having extra energy available earlier.

Before engaging with the flexibility market, the prosumer calculates the optimal schedule for its flexible energy resource in the retail market, $P_{i t}^{f}, t \in \mathcal{T}$, considering its constraints and preferences. This is envisaged as being automated and completed by an energy management system based on user controlled settings (see e.g. [44]). Note that a key component of an energy management system is a tool for local demand forecasting [49].

In the flexibility market, for upstream contracts $Y_{i}$ and downstream contracts $Z_{i}$, prosumer $i$ 's utility function is,

$$
\begin{aligned}
& U_{i}\left(Y_{i} \cup Z_{i}\right)=\sum_{\left(\omega, t_{\omega}, p_{\omega}\right) \in Z_{i}}\left(p_{\omega}+\gamma_{i} t_{\omega}\right)-\sum_{\left(\phi, t_{\phi}, p_{\phi}\right) \in Y_{i}}\left(p_{\phi}+\gamma_{i} t_{\phi}\right) \\
& +\sum_{t \in \mathcal{T}}\left[p_{i t}^{s}\left[P_{i t}^{f}-P_{i t}^{d}-\left|Y_{i t}\right|+\left|Z_{i t}\right|\right]^{+}\right. \\
& \left.-p_{i t}^{b}\left[P_{i t}^{d}-P_{i t}^{f}+\left|Y_{i t}\right|-\left|Z_{i t}\right|\right]^{+}-c_{2 i}\left(P_{i t}^{f}-\left|Y_{i t}\right|+\left|Z_{i t}\right|\right)^{2}\right], \\
& \text { if } \quad \underline{P}_{i t}^{f} \leq P_{i t}^{f}-\left|Y_{i t}\right|+\left|Z_{i t}\right| \leq \bar{P}_{i t}^{f}, \forall t \in \mathcal{T}, \\
& \quad \underline{E}_{i \tau} \leq E_{i 0}-\sum_{t=1}^{\tau}\left(P_{i t}^{f}-\left|Y_{i t}\right|+\left|Z_{i t}\right|\right) \leq \bar{E}_{i \tau}, \forall \tau \in \mathcal{T}, \\
& U_{i}\left(Y_{i} \cup Z_{i}\right)=-\infty, \quad \text { otherwise. }
\end{aligned}
$$

Quantities have per-contract units. For example, if each contract is associated with $0.5 \mathrm{kWh}$ of energy, then $P_{i t}^{f}, P_{i t}^{d}, E_{i 0}$ have units of $0.5 \mathrm{kWh}, p_{i t}^{s}, p_{i t}^{b}$ have units of $£ / 0.5 \mathrm{kWh}$ and $\gamma_{i}$ has units of $£ / 0.5 \mathrm{kWh} / \mathrm{h}$.

Within the proposed framework, alternative utility functions can be considered for prosumers with different energy resources or preferences. For example, prosumers may value having energy stored in their battery at the end of the trading period. This could be represented by an additional utility function term of form $u_{i E}\left(\sum_{t=1}^{T}\left(\left|Y_{i t}\right|-\left|Z_{i t}\right|-P_{i t}^{f}\right)\right.$ in (4), where $u_{i E}$ is the value placed on stored energy.

The proposed market design assumes that prior to the flexibility market, each prosumer calculates a retail market schedule for their flexible energy resources $P_{i t}^{f}, t \in \mathcal{T}$ which they would prefer in the absence of external rewards. For this paper, each prosumer's retail market schedule was calculated by reformulating (4) as a maximization problem, with decision variables $P_{i t}^{f}, t \in \mathcal{T}$, while $Y_{i t}=\varnothing, Z_{i t}=\varnothing, \forall t \in \mathcal{T}$ and with an additional utility term $\gamma_{i} \sum_{t \in \mathcal{T}} t P_{i t}^{f}$.

\section{B. DSO Preferences}

The trading network has a single DSO, $d \in \mathcal{A}$, which must manage minimum and maximum limits on the total distribution network demand during each time interval, $\left[\underline{P}_{t}^{D}, \bar{P}_{t}^{D}\right]$. The DSO buys flexibility contracts for time intervals when the predicted pre-flexibility market retail demand $P_{t}^{D}, t \in \mathcal{T}$, 
violates the maximum demand limits, and can sell contracts during unconstrained intervals. For upstream contracts $Y_{d}$ and downstream contracts $Z_{d}$, the DSO's utility function is given by,

$$
\begin{aligned}
& U_{d}\left(Y_{d} \cup Z_{d}\right)=\sum_{\left(\omega, t_{\omega}, p_{\omega}\right) \in Z_{d}} p_{\omega}-\sum_{\left(\phi, t_{\phi}, p_{\phi}\right) \in Y_{d}} p_{\phi}, \\
& \quad \text { if } \underline{P}_{t}^{D} \leq P_{t}^{D}-\left|Y_{d t}\right|+\left|Z_{d t}\right| \leq \bar{P}_{t}^{D}, \forall t \in \mathcal{T}, \\
& U_{d}\left(Y_{d} \cup Z_{d}\right)=-\infty, \quad \text { otherwise. }
\end{aligned}
$$

\section{Aggregator Preferences}

Let $\mathcal{S} \subseteq \mathcal{A}$ be the set of aggregators in the trading network. The aggregators act as intermediaries, buying and selling flexibility contracts from the DSO and prosumers. It is assumed that the aggregators do not consume, store or generate energy. Therefore, their total upstream and downstream contracts for each time interval must be balanced. It is assumed that aggregator $j \in \mathcal{S}$ incurs a transaction cost for each accepted upstream contract, $c_{1 j} \geq 0$.

In the flexibility market, for upstream contracts $Y_{j}$ and downstream contracts $Z_{j}$, aggregator $j$ 's utility function is given by,

$$
\begin{aligned}
& U_{j}\left(Y_{j} \cup Z_{j}\right)=\sum_{\left(\omega, t_{\omega}, p_{\omega}\right) \in Z_{j}} p_{\omega}-\sum_{\left(\phi, t_{\phi}, p_{\phi}\right) \in Y_{j}} p_{\phi}-c_{1 j}\left|Y_{j}\right|, \\
& \quad \text { if }\left|Y_{j t}\right|=\left|Z_{j t}\right|, \forall t \in \mathcal{T}, \\
& U_{j}\left(Y_{j} \cup Z_{j}\right)=-\infty, \quad \text { otherwise. }
\end{aligned}
$$

The aggregator preferences can be extended to handle situations where the aggregators have their own flexibile energy resources (e.g. community-scale energy storage systems [50]). In this case, the upstream-downstream contract balance constraint $\left|Y_{j t}\right|=\left|Z_{j t}\right|, \forall t \in \mathcal{T}$ would be replaced by the power and energy constraints from the prosumer preferences (4).

\section{MARKet Stability AND EFFICIENCY}

For a trading network with contracts $X$, an outcome is a feasible set of contracts $X^{\prime} \subseteq X$, where $X^{\prime}$ is feasible if each trade $\omega \in \tau\left(X^{\prime}\right)$ is associated with at most one contract, and therefore has a unique price.

A key aim for market design is to ensure stable outcomes exist, which agents are able to find through negotiation. If agents are not able to agree on a stable outcome within the market, they will have an incentive to leave and renegotiate outside of it [51]. This paper uses the definition for stable outcomes in matching markets from [52]:

Definition 1. An outcome $X^{\prime}$ is stable if it is:

1) Individually Rational: $X_{i}^{\prime} \in C_{i}\left(X^{\prime}\right)$ for all $i \in \mathcal{A}$.

2) Unblocked: There is no feasible non-empty set $B \subseteq X$, such that $B \cap X^{\prime}=\varnothing$ and $B_{i} \subseteq C_{i}\left(B \cup X^{\prime}\right), \forall i \in a(B)$

In other words, an outcome is stable as long as no agent would prefer to drop a contract they are associated with, and no group of agents would prefer to mutually deviate to a different set of contracts.
For upstream contracts $Y$ and downstream contracts $Z$, let agent $i$ 's rejected sets of upstream and downstream contracts be defined respectively as,

$$
\begin{aligned}
R_{i}^{B}(Y \mid Z) & =\left\{y \in Y \mid b(y)=i, y \notin C_{i}(Y \cup Z)\right\}, \\
R_{i}^{S}(Z \mid Y) & =\left\{z \in Z \mid s(z)=i, z \notin C_{i}(Y \cup Z)\right\} .
\end{aligned}
$$

In [52], it is shown that stable outcomes are guaranteed to exist when the preferences of the agents satisfy full substitutability.

Definition 2. The preferences of agent $i$ are fully substitutable if, for any upstream contracts $Y^{\prime} \subseteq Y$ and downstream contracts $Z^{\prime} \subseteq Z$, the agent's choice correspondence is:

1) Same-Side Substitutable:

$$
R_{i}^{B}\left(Y^{\prime} \mid Z\right) \subseteq R_{i}^{B}(Y \mid Z) \text { and } R_{i}^{S}\left(Z^{\prime} \mid Y\right) \subseteq R_{i}^{S}(Z \mid Y) .
$$

2) Cross-Side Complementary:

$$
R_{i}^{B}(Y \mid Z) \subseteq R_{i}^{B}\left(Y \mid Z^{\prime}\right) \text { and } R_{i}^{S}(Z \mid Y) \subseteq R_{i}^{S}\left(Z \mid Y^{\prime}\right) .
$$

In other words, an agent's preferences are fully substitutable if, when offered additional contracts, they continue to reject previously rejected same-side contracts, and continue to accept previously accepted cross-side contracts.

Theorem 1. The prosumer, generator and aggregator preferences described by (4), (5), (6) satisfy full substitutability.

Proof of Theorem 1: See the Appendix.

Note that stable outcomes coincide with competitive equilibria - sets of prices for transactions that balance supply and demand [52]. Also, since the agents can transfer utility through payments, stable outcomes are Pareto efficient, meaning no agent can be made better off without making another agent worse off [53].

\section{Price-Negotiation and Contract Selection}

The fact that the agent preferences are fully substitutable has two further consequences. First, the trading network can reach agreement on a stable outcome using the deferred-acceptance agent-to-agent price-negotiation mechanism from [54]. Second, agents can use a computationally scalable process to select sets of contracts that will maximize their utility, since their preferences satisfy the single improvement property [55].

\section{A. Price-Negotiation Mechanism}

The proposed flexibility market design requires only individual decision making and agent-to-agent negotiation between the DSO, aggregators and prosumers. Agents wishing to obtain flexibility make progressively higher offers to potential sellers, and sellers choose to accept or reject these offers. Each iteration, the prices of over-demanded flexibility trades increase by a minimum price-increment $\Delta p$, until each trade has been either selected by both its buyer and seller, or rejected by both its buyer and seller.

A flow chart of the price-negotiation process is shown in Fig. 2. Each agent $i \in \mathcal{A}$ starts by specifying the flexibility trades they may be willing to make. Let $\Omega$ be the full set of trades in the market. Each trade $\omega \in \Omega$ is assigned a buyer price $p_{\omega}^{b}$ and a seller price $p_{\omega}^{s}$. Initially, $p_{\omega}^{b}=0$ and $p_{\omega}^{s}=0$ for all $\omega \in \Omega$. The agents then engage in iterative negotiation with their neighbors. Each iteration: 


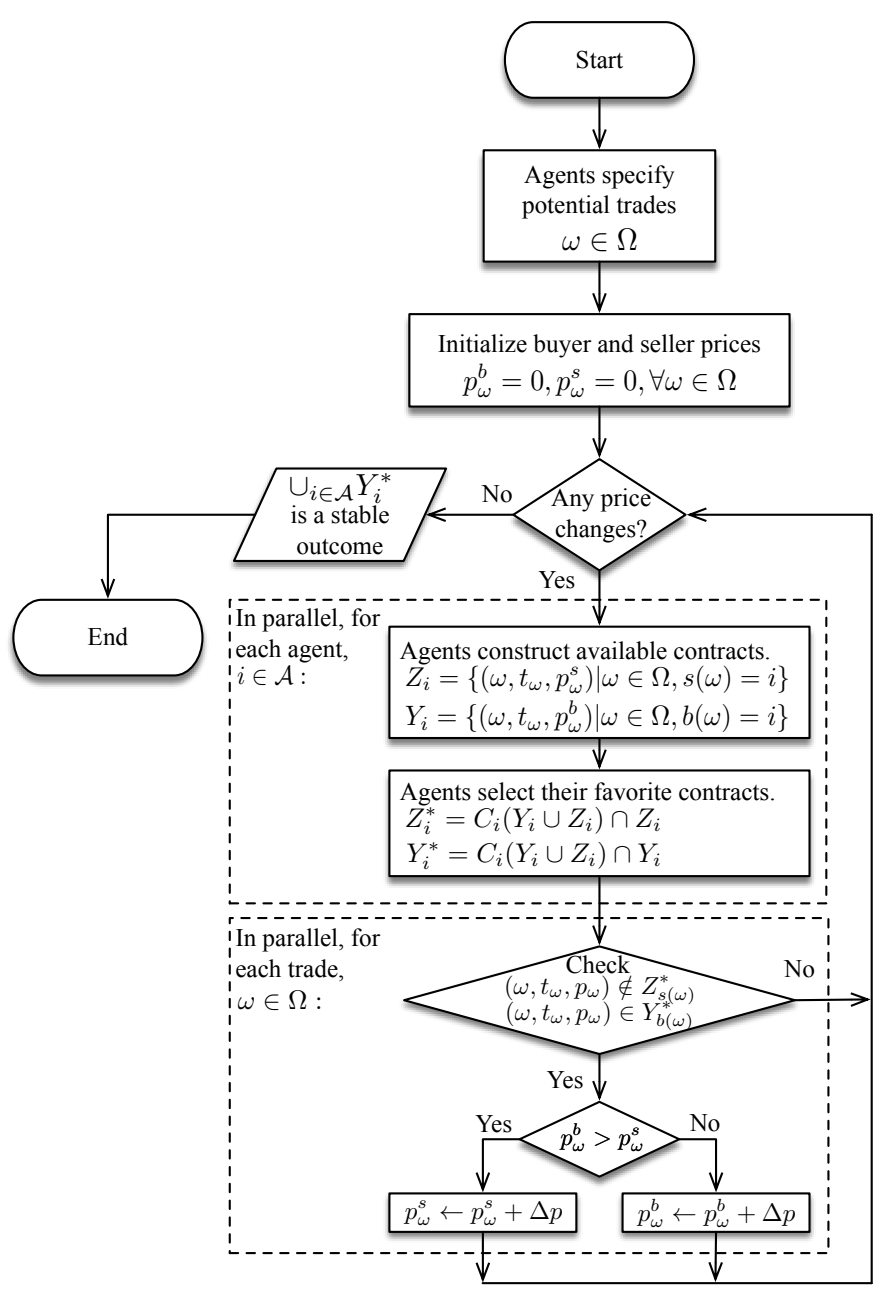

Fig. 2. A flow chart showing the agent-to-agent price-negotiation mechanism.

- Each agent $i \in \mathcal{A}$ constructs a set of upstream contracts to choose from, $Y_{i}=\left\{\left(\omega, t_{\omega}, p_{\omega}^{b}\right) \mid \omega \in \Omega, b(\omega)=i\right\}$ and a set of downstream contracts to choose from, $Z_{i}=$ $\left\{\left(\omega, t_{\omega}, p_{\omega}^{s}\right) \mid \omega \in \Omega, s(\omega)=i\right\}$.

- Each agent $i \in \mathcal{A}$ selects its favorite set of upstream contracts $Y_{i}^{*}=C_{i}\left(Y_{i} \cup Z_{i}\right) \cap Y_{i}$ and downstream contracts $Z_{i}^{*}=C_{i}\left(Y_{i} \cup Z_{i}\right) \cap Z_{i}$.

- The prices of over-demanded trades are increased. The set of over-demanded trades is given by $\Phi=\{\omega \in$ $\left.\Omega \mid\left(\omega, t_{\omega}, p_{\omega}\right) \in Y_{b(\omega)}^{*}, \omega \notin Z_{s(\omega)}^{*}\right\}$. For each $\omega \in \Phi$, if $p_{\omega}^{b}>p_{\omega}^{s}$, then $p_{\omega}^{s}$ is increased by $\Delta p$; otherwise, $p_{\omega}^{b}$ is increased by $\Delta p$.

The negotiation is complete when no price changes occur during an iteration. $\cup_{i \in \mathcal{A}} Y_{i}^{*}$ is a stable outcome for the trading network.

Note that if the prosumer resources have sufficient flexibility to satisfy the DSO's demand constraints, then the constraints will be satisfied at the end of the price-negotiation. The DSO will continue to offer higher prices for unrealized contracts required to meet its demand constraints, as long as the constraints are not satisfied. Eventually, these contracts will become sufficiently valuable, so that they are also selected by the associated prosumers and aggregators.

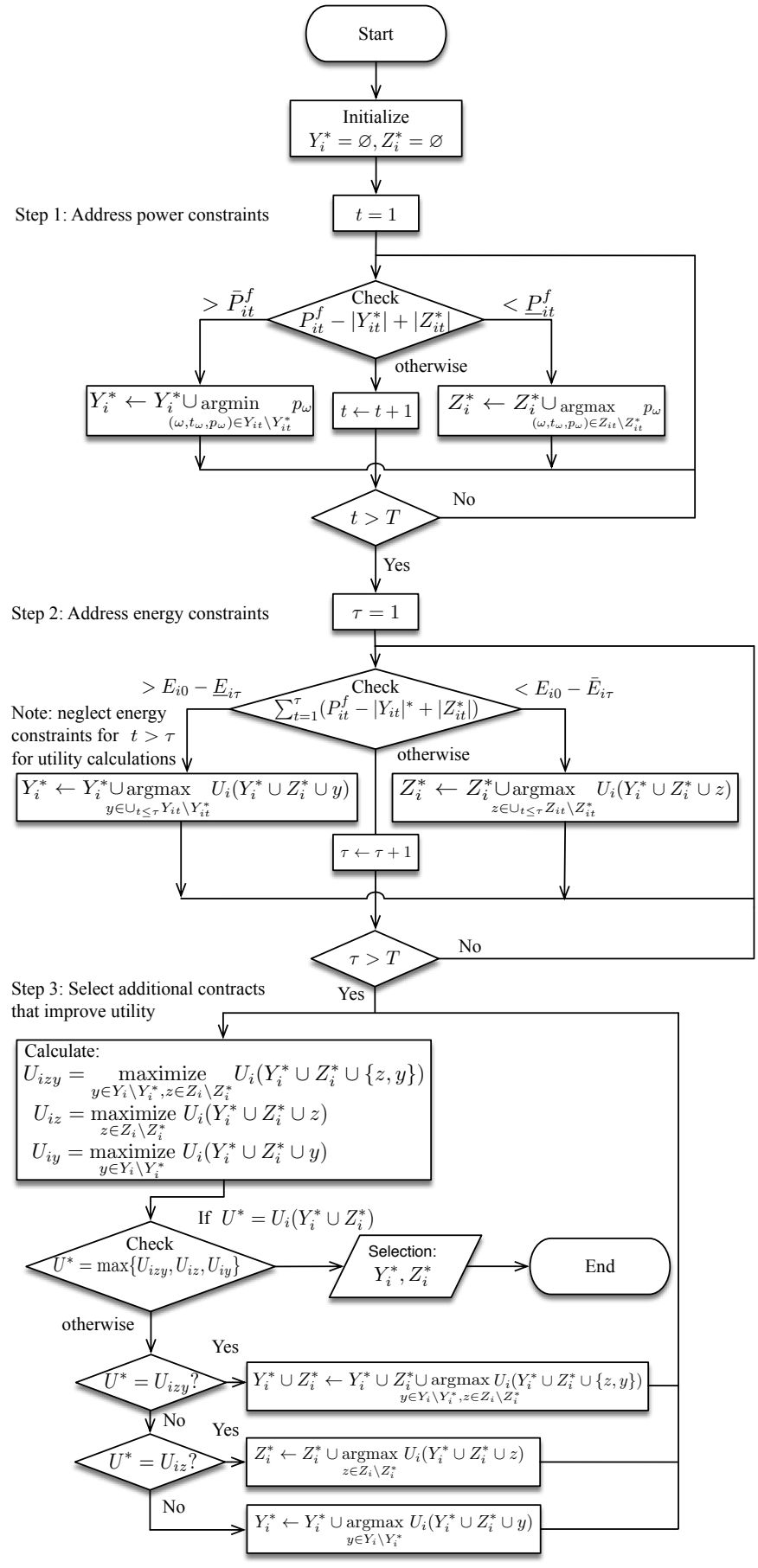

Fig. 3. A flow chart showing the contract selection process for the prosumers. Contract selection is similar for the DSO and aggregators, but without step 2 which addresses the prosumers' energy constraints.

\section{B. Contract Selection}

During each iteration of the price-negotiation mechanism, agents need to select a subset of contracts from those they are offered that will maximize their utility. Since the agent preferences satisfy full substitutability they also satisfy the single improvement property [55].

Definition 3. Agent $i$ 's preferences satisfy the single improvement property if, for any suboptimal subset of contracts $X^{\prime}$, such that $U_{i}\left(X^{\prime}\right) \neq-\infty$, the agent can increase their utility 
by making one of the following local adjustments:

1) Adding or removing a single upstream or downstream contract.

2) Adding or removing both an upstream and downstream contract.

Given the single improvement property, the agents can use the following process to select utility-maximizing contract subsets. A flow chart of the contract selection process for the prosumers is shown in Fig. 3.

First, the agents need to ensure their constraints are not violated. The prosumers and DSO have maximum power limits. For each time interval when their maximum power limit is violated, they should select upstream contracts starting with the lowest priced contracts, until the violation is cleared. Similarly, high priced downstream contracts should be selected for each time interval until their minimum power limits are not violated.

The prosumers also need to ensure their energy storage constraints are not violated. The prosumers should identify the time intervals when their energy storage limits are violated, and should clear each violation in order from earliest to latest. To clear maximum energy violations, prosumers should select downstream contracts for preceding intervals, ensuring they do not introduce new power or energy constraint violations. The downstream contracts with the highest prices available at each suitable time interval should be compared, to see which gives the greatest increase in marginal utility for the unconstrained utility function. Similarly, the prosumers should select low priced upstream constraints to clear minimum energy level violations.

Once the agents have selected the minimum number of contracts necessary to meet their constraints, they should select additional contracts which increase their utility. Iteratively, the agents need to assess the marginal utility provided by each of the lowest priced upstream contracts still available at each time interval, the highest priced downstream contracts still available at each interval and upstream-downstream pairs of these contracts. The option or options providing the greatest increase in utility should be selected. When none of these options provides further utility, a utility maximizing subset of contracts has been selected.

\section{Results}

Simulation case studies were completed to verify the operation of the proposed market design, using the IEEE European Low Voltage Test Feeder [56]. As shown in Fig. 4, the distribution network has 55 prosumers. Prosumers 1-30 have 4 $\mathrm{kW}$ PV sources and $4 \mathrm{kWh}, 2 \mathrm{~kW}$ rated home battery systems, prosumers 31-45 have electric vehicles which they charge at home using $3 \mathrm{~kW}$ unidirectional chargers and prosumers 4655 do not have flexible energy resources. Two case studies are presented, Case Study A which considers batteries with a relatively low cost of degradation, and Case Study B which considers batteries with a higher cost of degradation.

The IEEE European Low Voltage Test Feeder is $415 \mathrm{~V}$ $50 \mathrm{~Hz}$ 3-phase UK distribution feeder, with 55 single-phase

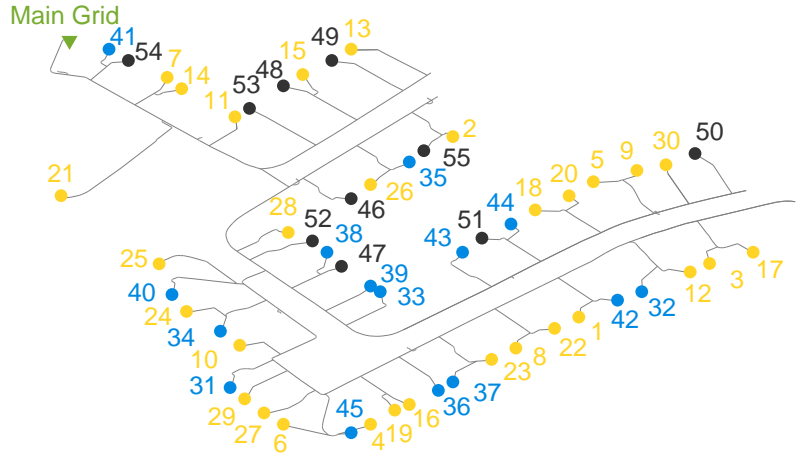

Main grid point of common coupling.

Prosumers 1-30: $4 \mathrm{~kW}$ PV sources and $2 \mathrm{~kW}, 4 \mathrm{kWh}$ batteries.

Prosumers 31-45: Electric vehicles and $3 \mathrm{~kW}$ unidirectional chargers.

Prosumers 46-55: No flexible energy resources.

Fig. 4. IEEE European Low Voltage Test Feeder with 55 prosumers.

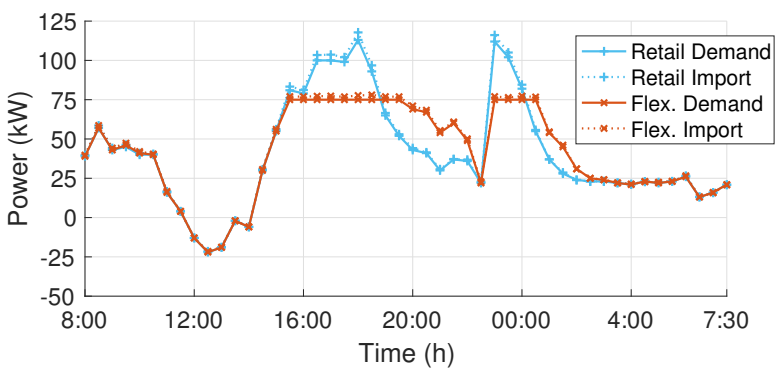

Fig. 5. Case Study A (low battery degradation): The total prosumer demand planned in the retail market, and the demand following the flexibility market. For each case, the additional power imported from the main grid due to losses is also shown.

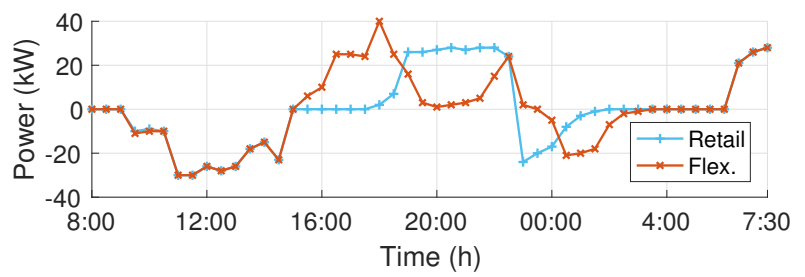

Fig. 6. Case Study A (low battery degradation): The total home battery output power for prosumers 1-30 planned in the retail market and following the flexibility market.

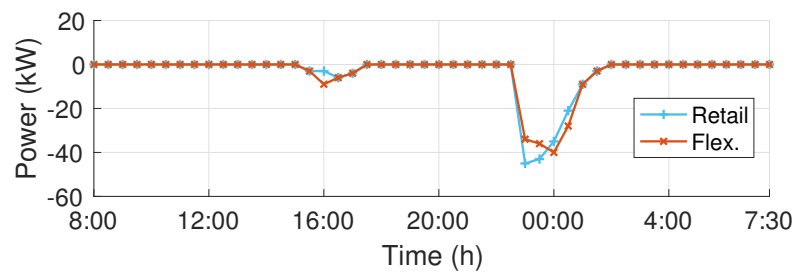

Fig. 7. Case Study A (low battery degradation): The total electric vehicle output power for prosumers $31-45$ planned in the retail market and following the flexibility market.

consumers. For the case studies, the flexibility market is implemented to allow the DSO to manage the combined demand across the three phases. The flexibility market is designed based on a simplified model of distribution network demand. 


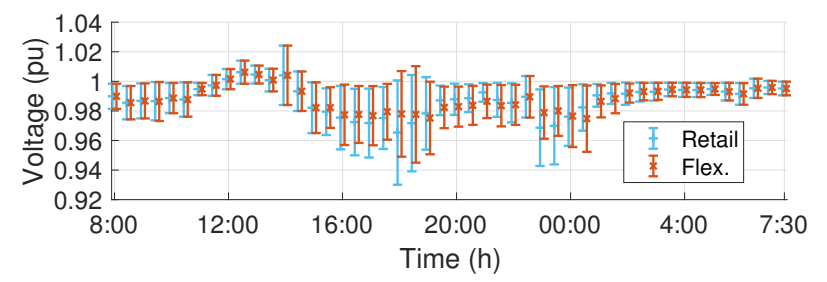

Fig. 8. Case Study A (low battery degradation): The range of voltage magnitudes across the distribution network load buses due to the planned retail market demand and the demand following the flexibility market.

For realistic verification, the power flows, losses and voltages resulting from the market outcome have been calculated using a 3-phase unbalanced power flow model [57].

The DSO organizes a flexibility market to limit the distribution network demand to $75 \mathrm{~kW}$. There are two aggregators acting as intermediaries between the DSO and the prosumers. Aggregator 1 trades with prosumers 1-30 (the prosumers with home batteries) and aggregator 2 trades with prosumers $31-$ 45 (the prosumers with electric vehicles). Note that prosumers 46-55 do not participate in the flexibility market since they do not have flexible energy resources.

Smart meter data from the UK Customer-Led Network Revolution project was used for the prosumer load and PV generation profiles [58]. Data made available by NREL was used for the energy required by the electric vehicles [59]. Vehicle arrival and departure times were generated randomly, assuming normal distributions with mean times of $6 \mathrm{pm}$ and 7 am respectively, and one hour standard deviations.

The prosumers face time-of-use dependent retail energy prices of $£ 0.15 / \mathrm{kWh}$ from 7 am to $11 \mathrm{pm}$ and $£ 0.07 / \mathrm{kWh}$ from $11 \mathrm{pm}$ to $7 \mathrm{am}$. The prosumers are paid a feed-in rate of $£ 0.04 / \mathrm{kWh}$ for excess energy they export.

The flexibility market occurs over a 24 hour period (from 8 am to $8 \mathrm{am}$ ), with contracts specifying an agreed decrease in load by $1 \mathrm{~kW}$ during a particular 30 minute interval. A market price increment of $\Delta p=£ 0.005 / \mathrm{kWh}$ is used. For prosumers $1-30$, the increased battery degradation that occurs at higher output powers is modeled with a quadratic cost coefficient $c_{2 i}$. For Case Study A, $c_{2 i}=£ 0.01 /(\mathrm{kWh})^{2}$, whereas in Case Study B the rate of degradation is higher, $c_{2 i}=£ 0.06$ $/(\mathrm{kWh})^{2}$. It is assumed the batteries start at their minimum energy level at 8 am and must be returned to this energy level by 8 am the next day. For prosumers $31-45$, it is assumed they need to fully re-charge their electric vehicles between their arrival and departure times, and also have a preference for early charging, with $\gamma_{i}=£ 0.01 / \mathrm{kWh} / \mathrm{h}$. The aggregators incur a transaction cost of $c_{1 i}=£ 0.01$ for each accepted upstream contract.

Each prosumer has a different load profile, and the electric vehicle owners each have a different arrival time, departure time and energy requirement for their vehicle. Common cost coefficients have been used for the prosumers of each type, so that the impact of changing the degradation cost coefficient values is clear between the two case studies. However, the market design does not restrict agents from having different utility functions and different cost coefficients. In particular, there are significant differences between the utility functions of prosumers 1-30 (the prosumers with home batteries) compared with prosumers $31-45$ (the prosumers with electric vehicles).

For Case Study A, Fig. 5 shows the total prosumer demand planned in the retail market, and the demand following the flexibility market. For each case, the additional power imported from the main grid due to losses is also shown. In the retail market, demand peaks occur at $6 \mathrm{pm}$ and 11 pm. The $11 \mathrm{pm}$ peak is caused by electric vehicle owners waiting for the lower retail price period before charging. In the flexibility market, the DSO incentivizes the prosumers to shift their flexible loads so that the $75 \mathrm{~kW}$ maximum demand limit is not violated.

Fig. 6 shows the total home battery output power for prosumers 1-30 planned in the retail market and following the flexibility market. Fig. 7 shows the total electric vehicle output power for prosumers 31-45. Through the flexibility market, the battery owners are incentivized to discharge their batteries earlier to flatten the $6 \mathrm{pm}$ demand peak. Also, the battery owners have a second charging cycle which is shifted later (but still within the period with low retail prices) so that it does not coincide with the electric vehicles' 11 pm charging cycle. Only a small amount of electric vehicle demand is shifted, since the electric vehicle owners prefer early charging and therefore would require more compensation to provide the same level of flexibility as the prosumers with home batteries.

Fig. 8 shows the range of voltage magnitudes across the distribution network load buses due to the planned retail market demand and the demand following the flexibility market. The peak-shaving facilitated by the flexibility market increases the minimum voltage magnitude from $0.930 \mathrm{pu}$ to $0.945 \mathrm{pu}$.

For Case Study B, when the battery energy storage systems have a higher degradation cost, Fig. 9 shows the total prosumer demand. As shown in Fig. 10, the higher battery degradation cost results in reduced battery utilisation being planned in the retail market, relative to Case Study A. In the flexibility market, the batteries are charged when PV generation is available, and discharged to maintain the $75 \mathrm{~kW}$ demand limit. Fig. 11 shows that the electric vehicle charging profiles are similar between the two case studies. As shown in Fig. 12, the flexibility market results in lower voltage rise due to a reduction in exported $\mathrm{PV}$ generation.

Fig. 13 shows the total revenue accumulated by different groups of agents in the flexibility market. Most of the flexibility is provided by the prosumers with battery systems (prosumers 1-30), and thus they accumulate more revenue than the prosumers with electric vehicles (prosumers 31-45). Aggregator 1, which trades with prosumers 1-30, receives more revenue than aggregator 2 , since it is responsible for coordinating more transactions. The revenue accumulated by the prosumers and aggregators is matched by the payments made by the DSO. Prosumers 46-55 receive no revenue since they do not participate in the flexibility market. Prosumers 1-30 recieve significantly more revenue during Case Study B since they must be compensated for their higher battery degradation costs. 


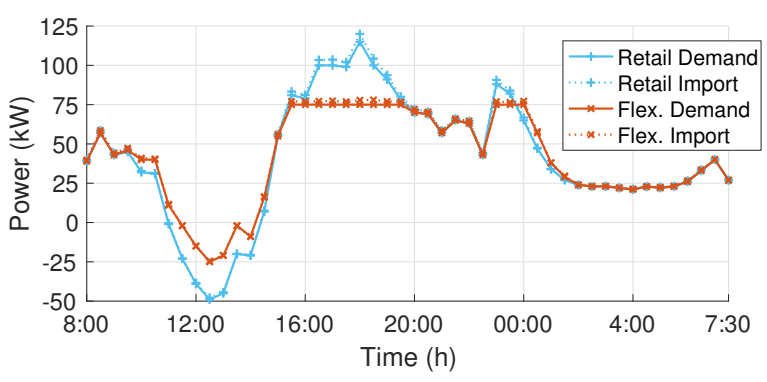

Fig. 9. Case Study B (high battery degradation): The total prosumer demand planned in the retail market, and the demand following the flexibility market. For each case, the additional power imported from the main grid due to losses is also shown.

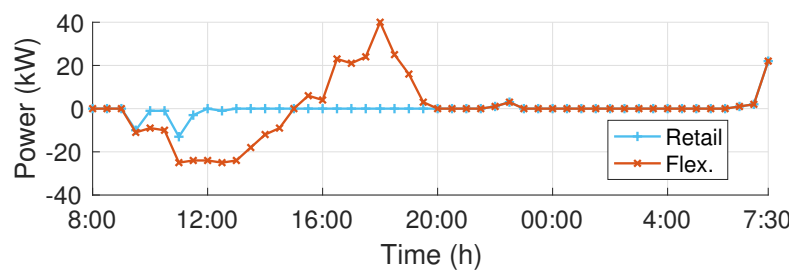

Fig. 10. Case Study B (high battery degradation): The total home battery output power for prosumers $1-30$ planned in the retail market and following the flexibility market.

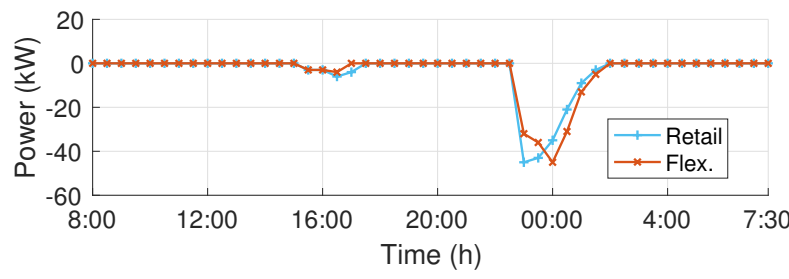

Fig. 11. Case Study B (high battery degradation): The total electric vehicle output power for prosumers $31-45$ planned in the retail market and following the flexibility market.

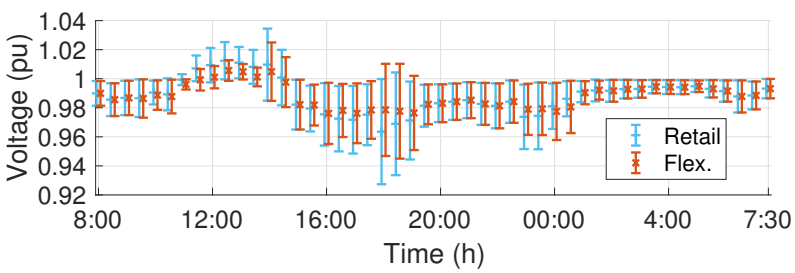

Fig. 12. Case Study B (high battery degradation): The range of voltage magnitudes across the distribution network load buses due to the planned retail market demand and the demand following the flexibility market.

\section{CONCLUSION}

A decentralized market design has been presented, allowing a DSO to manage local demand constraints by obtaining flexibility from a supply chain of aggregators and prosumers with small-scale flexible energy resources. A key advantage of the proposed market design is that it can be implemented alongside existing retail electricity market arrangements. The market design could help integrate flexibility from prosumers with preferences for autonomy and privacy, since it requires only individual decision making and aggregator-to-prosumer

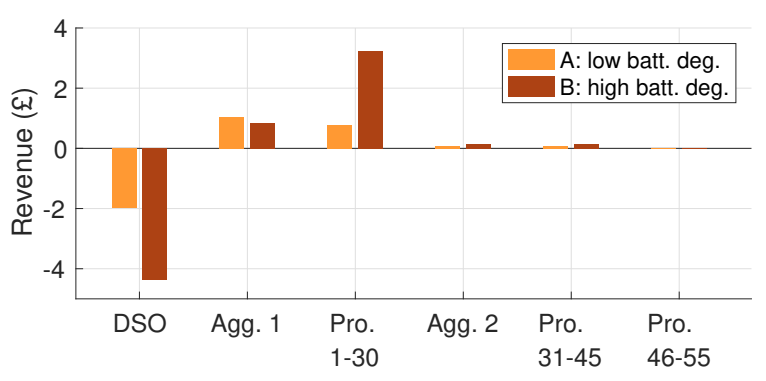

Fig. 13. The total revenue accumulated by different groups of agents in the flexibility market during case studies A and B.

negotiation. Prosumers can individually decide whether to participate or not, and the conditions under which they are willing to provide flexibility.

A limitation of the design is that it only allows the DSO to manage the overall distribution network demand. Reducing peak demand still approximately addresses voltage limits and power flow limits at the transformer. Also, it has the potential advantages of not requiring a detailed network model and treating flexibility provided by prosumers equally. However, there is a trade-off when considering the proposed market design, compared with centralized designs with more detailed distribution network models that directly account for losses, reactive power flows and voltage limits.

An interesting area for future work is whether the pricenegotiation mechanism can be sped up by allowing for asynchronous price adjustments, while mitigating the trade-off with economic efficiency. Detailed assessments of the required ICT infrastructure and associated costs will be required prior to implementation. Since the market design is underpinned by bilateral transactions, it could also be integrated into future P2P electricity markets.

\section{APPENDIX}

In this appendix, it is shown that the prosumer, DSO and aggregator preferences from Section III satisfy full substitutability. The following definition for an agent's indirect utility function, from [55], is needed.

Definition 4. The indirect utility function of agent $i$ is given by $V_{i}(p)=\max _{\Psi \subseteq \Omega_{i}}\left\{U_{i}(\kappa([\Psi \mid p]))\right\}$, where $\Omega_{i}$ is the set of trades that are available for agent $i$ to buy or sell, $p$ is a vector of prices for all trades in the market, $\Psi \subseteq \Omega_{i}$ is a subset of available trades which maximize agent $i$ 's utility and $\kappa([\Psi \mid p])$ gives the set of contracts associated with $\Psi \subseteq \Omega_{i}$, given the price vector $p$.

The preferences of an agent are fully substitutable, if and only if they induce a submodular indirect utility function $V_{i}$. To show $V_{i}$ is submodular, it is enough to show that for any two trades $\phi, \psi \in \Omega_{i}$ and prices $p_{\Omega_{i}^{\prime}} \in \mathbb{R}^{\left|\Omega_{i} \backslash\{\psi, \phi\}\right|}, p_{\phi}^{h} \geq p_{\phi}$, $p_{\psi}^{h} \geq p_{\psi}[55]$

$$
\begin{aligned}
& V_{i}\left(p_{\Omega_{i}^{\prime}}, p_{\phi}, p_{\psi}^{h}\right)-V_{i}\left(p_{\Omega_{i}^{\prime}}, p_{\phi}^{h}, p_{\psi}^{h}\right) \geq \\
& V_{i}\left(p_{\Omega_{i}^{\prime}}, p_{\phi}, p_{\psi}\right)-V_{i}\left(p_{\Omega_{i}^{\prime}}, p_{\phi}^{h}, p_{\psi}\right) .
\end{aligned}
$$

The following contracts are introduced, $y_{\phi}=\left(\phi, t_{\phi}, p_{\phi}\right), y_{\psi}=$ $\left(\psi, t_{\psi}, p_{\psi}\right), z_{\phi}=\left(\phi, t_{\phi}, p_{\phi}^{h}\right), z_{\psi}=\left(\psi, t_{\psi}, p_{\psi}^{h}\right)$. 
Proof of Theorem 1. First, a generic agent utility function $U_{i}^{\prime}$ is formulated, based on the prosumer utility function (4), with the cost term $-c_{1 i}\left|Y_{i}\right|$ from the aggregator utility function (6) added in. The prosumer, DSO and aggregator utility functions (4), (5), (6) are special cases of $U_{i}^{\prime}$.

Given agent utility functions with form $U_{i}^{\prime}$, the marginal utility provided by a contract only depends on: (i) its price; (ii) the difference between the number of previously accepted upstream and downstream contracts with the same time interval; and (iii) the difference between the total number of previously accepted upstream and downstream contracts with the same time interval or a preceding one. Therefore, when an additional upstream (or downstream) contract becomes available, the net number of upstream (or downstream) contracts will either increase by one or stay the same (depending on whether the contract is accepted, accepted instead of a previously accepted contract of the same type, accepted along with a previously rejected contract of the opposite type, or rejected). Therefore, to show that preferences described by $U_{i}^{\prime}$ satisfy (9), it is sufficient to show that (10)-(13) are satisfied.

$$
\begin{aligned}
& U_{i}^{\prime}\left(Y_{\phi i}^{\prime} \cup Z_{i} \cup y_{\phi}\right)-U_{i}^{\prime}\left(Y_{i} \cup Z_{i}\right) \\
& \quad \geq U_{i}^{\prime}\left(Y_{i}^{\prime \prime} \cup Z_{i} \cup y_{\phi} \cup y_{\psi}\right)-U_{i}^{\prime}\left(Y_{\psi i}^{\prime} \cup Z_{i} \cup y_{\psi}\right), \\
& U_{i}^{\prime}\left(Y_{\phi i}^{\prime} \cup Z_{\psi i}^{\prime} \cup y_{\phi} \cup z_{\psi}\right)-U_{i}^{\prime}\left(Y_{i} \cup Z_{i}^{\prime \prime} \cup z_{\psi}\right) \\
& \quad \geq U_{i}^{\prime}\left(Y_{i}^{\prime \prime} \cup Z_{i} \cup y_{\phi}\right)-U_{i}^{\prime}\left(Y_{i} \cup Z_{i}\right), \\
& U_{i}^{\prime}\left(Y_{i} \cup Z_{i}\right)-U_{i}^{\prime}\left(Y_{i} \cup Z_{i}^{\prime \prime} \cup z_{\phi}\right) \\
& \quad \geq U_{i}^{\prime}\left(Y_{i}^{\prime \prime} \cup Z_{i} \cup y_{\psi}\right)-U_{i}^{\prime}\left(Y_{\psi i}^{\prime} \cup Z_{\phi i}^{\prime} \cup z_{\phi} \cup y_{\psi}\right), \\
& U_{i}^{\prime}\left(Y_{i} \cup Z_{\psi i}^{\prime} \cup z_{\psi}\right)-U_{i}^{\prime}\left(Y_{i} \cup Z_{i}^{\prime \prime} \cup z_{\phi} \cup z_{\psi}\right) \\
& \quad \geq U_{i}^{\prime}\left(Y_{i} \cup Z_{i}\right)-U_{i}^{\prime}\left(Y_{i} \cup Z_{\phi i}^{\prime} \cup z_{\phi}\right),
\end{aligned}
$$

where upstream contracts $y_{\phi}, y_{\psi} \notin Y_{i}, Y_{i}^{\prime \prime} \subseteq Y_{\phi i}^{\prime} \subseteq Y_{i}, Y_{i}^{\prime \prime} \subseteq$ $Y_{\psi i}^{\prime} \subseteq Y_{i},\left|Y_{i}\right| \leq\left|Y_{\phi i}^{\prime}\right|+1 \leq\left|Y_{i}^{\prime \prime}\right|+2$, and $\left|Y_{i}\right| \leq\left|Y_{\psi i}^{\prime}\right|+1 \leq$ $\left|Y_{i}^{\prime \prime}\right|+2$. Also, downstream contracts $z_{\phi}, z_{\psi} \notin Z_{i}, Z_{i}^{\prime \prime} \subseteq$ $Z_{\phi i}^{\prime} \subseteq Z_{i}, Z_{i}^{\prime \prime} \subseteq Z_{\psi i}^{\prime} \subseteq Z_{i},\left|Z_{i}\right| \leq\left|Z_{\phi i}^{\prime}\right|+1 \leq\left|Z_{i}^{\prime \prime}\right|+2$ and $\left|Z_{i}\right| \leq\left|Z_{\psi i}^{\prime}\right|+1 \leq\left|Z_{i}^{\prime \prime}\right|+2$.

Conditions (10)-(13) reflect (9) when $\phi, \psi$ are upstream trades and are selected at $p_{\phi}, p_{\psi}$, but not $p_{\phi}^{h}, p_{\psi}^{h}$, and when $\phi, \psi$ are downstream trades and selected at $p_{\phi}^{h}, p_{\psi}^{h}$, but not $p_{\phi}, p_{\psi}$. Note that for cases when $\phi$ is selected or rejected at both $p_{\phi}, p_{\phi}^{h}$ and/or $\psi$ is selected at both $p_{\psi}, p_{\psi}^{h}$, (9) results in an equality.

Let $\bar{z}_{i t}=P_{i t}^{f}-\left|Y_{i t}\right|+\left|Z_{i t}\right|$ and let $p_{i t}^{b}=p_{i t}^{s}+\alpha_{t} \geq 0$, where $\alpha_{t} \geq 0$.

First, to show (10) is true, 5 cases need to be considered:

Case 1: $\left|Y_{i}^{\prime \prime}\right|=\left|Y_{\phi i}^{\prime}\right|=\left|Y_{\psi i}^{\prime}\right|=\left|Y_{i}\right|$. When $t_{\phi} \neq t_{\psi}$, (10) results in an equality. When $t_{\phi}=t_{\psi}$, (10) requires,

$$
\begin{aligned}
& -\alpha_{t_{\phi}}\left[P_{i t_{\phi}}^{d}-\bar{z}_{i t_{\phi}}+1\right]^{+}-c_{2 i}\left(\bar{z}_{i t_{\phi}}-1\right)^{2}+\alpha_{t_{\phi}}\left[P_{i t_{\phi}}^{d}-\bar{z}_{i t_{\phi}}\right]^{+} \\
& +c_{2 i}\left(\bar{z}_{i t_{\phi}}\right)^{2} \geq-\alpha_{t_{\phi}}\left[P_{i t_{\phi}}^{d}-\bar{z}_{i t_{\phi}}+2\right]^{+}-c_{2 i}\left(\bar{z}_{i t_{\phi}}-2\right)^{2} \\
& +\alpha_{t_{\phi}}\left[P_{i t_{\phi}}^{d}-\bar{z}_{i t_{\phi}}+1\right]^{+}+c_{2 i}\left(\bar{z}_{i t_{\phi}}-1\right)^{2}
\end{aligned}
$$

which is true for all $\alpha_{t_{\phi}} \geq 0, c_{2 i} \geq 0$ and $P_{i t_{\phi}}^{d}, \bar{z}_{i t_{\phi}} \in \mathbb{Z}$.

Case 2: $\left|Y_{\psi i}^{\prime}\right|=\left|Y_{i}\right|$ and $\left|Y_{i}^{\prime \prime}\right|=\left|Y_{\phi i}^{\prime}\right|=\left|Y_{i}\right|-1$. In this case, $t_{\phi} \neq t_{\psi}$ since $\left|Y_{\psi i}^{\prime}\right| \neq\left|Y_{\phi i}^{\prime}\right|$. Condition (10) results in an equality.
Case 3: $\left|Y_{\phi i}^{\prime}\right|=\left|Y_{i}\right|$ and $\left|Y_{i}^{\prime \prime}\right|=\left|Y_{\psi i}^{\prime}\right|=\left|Y_{i}\right|-1$. In this case, $t_{\phi} \neq t_{\psi}$ since $\left|Y_{\psi i}^{\prime}\right| \neq\left|Y_{\phi i}^{\prime}\right|$. Condition (10) results in an equality.

Case 4: $\left|Y_{\phi i}^{\prime}\right|=\left|Y_{\psi i}^{\prime}\right|=\left|Y_{i}\right|-1$ and $\left|Y_{i}^{\prime \prime}\right|=\left|Y_{i}\right|-2$. For both $t_{\phi}=t_{\psi}$ and $t_{\phi} \neq t_{\psi}$, condition (10) results in an equality.

Case 5: $\left|Y_{\phi i}^{\prime}\right|=\left|Y_{\psi i}^{\prime}\right|=\left|Y_{i}\right|$ and $\left|Y_{i}^{\prime \prime}\right|=\left|Y_{i}\right|-1$. Let $Y_{i}=Y_{i}^{\prime \prime} \cup\left(h, t_{h}, p_{h}\right)$. Condition (10) requires,

$$
\begin{aligned}
& -p_{i t_{h}}^{s}-\alpha_{t_{h}}\left[P_{i t_{h}}^{d}-\bar{z}_{i t_{h}}+\beta\right]^{+}-c_{2 i}\left(\bar{z}_{i t_{h}}-\beta\right)^{2}-c_{1 i}-p_{h} \\
& -\gamma_{i} t_{h} \geq-\alpha_{t_{h}}\left[P_{i t_{h}}^{d}-\bar{z}_{i t_{h}}-1+\beta\right]^{+}-c_{2 i}\left(\bar{z}_{i t_{h}}+1-\beta\right)^{2}
\end{aligned}
$$

where $\beta=0$ if $t_{h} \neq t_{\phi}$ and $t_{h} \neq t_{\psi}$, and $\beta=1$ otherwise. This is true, since $U_{i}^{\prime}\left(Y_{i} \cup Z_{i} \cup y_{\phi}\right) \geq U_{i}^{\prime}\left(Y_{i}^{\prime \prime} \cup Z_{i} \cup y_{\phi}\right)$ and $U_{i}^{\prime}\left(Y_{i} \cup Z_{i} \cup y_{\psi}\right) \geq U_{i}^{\prime}\left(Y_{i}^{\prime \prime} \cup Z_{i} \cup y_{\psi}\right)$, and therefore contract $\left(h, t_{h}, p_{h}\right)$ provides non-negative marginal utility when selected alongside either $\left\{Z_{i} \cup Y_{i}^{\prime \prime} \cup y_{\phi}\right\}$ or $\left\{Z_{i} \cup Y_{i}^{\prime \prime} \cup y_{\psi}\right\}$.

To show (11) is true, 4 cases need to be considered:

Case 1: $\left|Y_{i}^{\prime \prime}\right|=\left|Y_{\phi i}^{\prime}\right|=\left|Y_{i}\right|,\left|Z_{i}^{\prime \prime}\right|=\left|Z_{\psi i}^{\prime}\right|=\left|Z_{i}\right|$. When $t_{\phi} \neq t_{\psi}$, (11) results in an equality. When $t_{\phi}=t_{\psi}$, (11) requires,

$$
\begin{aligned}
& -\alpha_{t_{\phi}}\left[P_{i t_{\phi}}^{d}-\bar{z}_{i t_{\phi}}\right]^{+}-c_{2 i}\left(\bar{z}_{i t_{\phi}}\right)^{2}+\alpha_{t_{\phi}}\left[P_{i t_{\phi}}^{d}-\bar{z}_{i t_{\phi}}-1\right]^{+} \\
& +c_{2 i}\left(\bar{z}_{i t_{\phi}}+1\right)^{2} \geq-\alpha_{t_{\phi}}\left[P_{i t_{\phi}}^{d}-\bar{z}_{i t_{\phi}}+1\right]^{+}-c_{2 i}\left(\bar{z}_{i t_{\phi}}-1\right)^{2} \\
& +\alpha_{t_{\phi}}\left[P_{i t_{\phi}}^{d}-\bar{z}_{i t_{\phi}}\right]^{+}+c_{2 i}\left(\bar{z}_{i t_{\phi}}\right)^{2}
\end{aligned}
$$

which is true for all $\alpha_{t_{\phi}} \geq 0, c_{2 i} \geq 0$ and $P_{i t_{\phi}}^{d}, \bar{z}_{i t_{\phi}} \in \mathbb{Z}$.

Case 2: $\left|Y_{i}^{\prime \prime}\right|=\left|Y_{\phi i}^{\prime}\right|=\left|Y_{i}\right|,\left|Z_{i}^{\prime \prime}\right|+1=\left|Z_{\psi i}\right|=\left|Z_{i}\right|$. Let $Z_{i}=Z_{i}^{\prime \prime} \cup\left(l, t_{l}, p_{l}\right)$. Condition (11) requires,

$$
\begin{aligned}
& p_{i t_{l}}^{s}-\alpha_{t_{l}}\left[P_{i t_{l}}^{d}-\bar{z}_{i t_{l}}-\beta\right]^{+}-c_{2 i}\left(\bar{z}_{i t_{l}}+\beta\right)^{2}+p_{l} \\
& +\gamma_{i} t_{l} \geq-\alpha_{t_{l}}\left[P_{i t_{l}}^{d}-\bar{z}_{i t_{l}}+1-\beta\right]^{+}-c_{2 i}\left(\bar{z}_{i t_{l}}-1+\beta\right)^{2}
\end{aligned}
$$

where $\beta=1$ if $t_{l}=t_{\psi} \neq t_{\phi}$, and $\beta=0$ otherwise. This is true, since $U_{i}^{\prime}\left(Y_{i} \cup Z_{i} \cup y_{\phi} \cup z_{\psi}\right) \geq U_{i}^{\prime}\left(Y_{i} \cup Z_{i}^{\prime \prime} \cup y_{\phi} \cup z_{\psi}\right)$, and therefore contract $\left(l, t_{l}, p_{l}\right)$ provides non-negative marginal utility when selected alongside $\left\{Y_{i} \cup Z_{i}^{\prime \prime} \cup y_{\phi} \cup z_{\psi}\right\}$.

Case 3: $\left|Y_{i}^{\prime \prime}\right|+1=\left|Y_{\phi i}^{\prime}\right|=\left|Y_{i}\right|,\left|Z_{i}^{\prime \prime}\right|=\left|Z_{\psi i}\right|=\left|Z_{i}\right|$. Let $Y_{i}=Y_{i}^{\prime \prime} \cup\left(h, t_{h}, p_{h}\right)$. Condition (11) requires,

$$
\begin{aligned}
& -p_{i t_{h}}^{s}-\alpha_{t_{h}}\left[P_{i t_{h}}^{d}-\bar{z}_{i t_{h}}+\beta\right]^{+}-c_{2 i}\left(\bar{z}_{i t_{h}}-\beta\right)^{2}-c_{1 i}-p_{h} \\
& -\gamma_{i} t_{h} \geq-\alpha_{t_{h}}\left[P_{i t_{h}}^{d}-\bar{z}_{i t_{h}}-1+\beta\right]^{+}-c_{2 i}\left(\bar{z}_{i t_{h}}+1-\beta\right)^{2}
\end{aligned}
$$

where $\beta=1$ if $t_{h}=t_{\phi} \neq t_{\psi}$, and $\beta=0$ otherwise. This is true, since $U_{i}^{\prime}\left(Y_{i} \cup Z_{i} \cup y_{\phi} \cup z_{\psi}\right) \geq U_{i}^{\prime}\left(Y_{i}^{\prime \prime} \cup Z_{i} \cup y_{\phi} \cup z_{\psi}\right)$, and therefore contract $\left(h, t_{h}, p_{h}\right)$ provides non-negative marginal utility when selected alongside $\left\{Y_{i}^{\prime \prime} \cup Z_{i} \cup y_{\phi} \cup z_{\psi}\right\}$.

Case 4: $\left|Y_{i}^{\prime \prime}\right|=\left|Y_{\phi i}^{\prime}\right|=\left|Y_{i}\right|-1,\left|Z_{i}^{\prime \prime}\right|=\left|Z_{\psi i}\right|=\left|Z_{i}\right|-1$. For both $t_{\phi}=t_{\psi}$ and $t_{\phi} \neq t_{\psi}$, condition (11) results in an equality.

To show (12) is true, 4 cases need to be considered:

Case 1: $\left|Y_{i}^{\prime \prime}\right|=\left|Y_{\psi i}^{\prime}\right|=\left|Y_{i}\right|,\left|Z_{i}^{\prime \prime}\right|=\left|Z_{\phi i}^{\prime}\right|=\left|Z_{i}\right|$. When $t_{\phi} \neq t_{\psi}$, (12) results in an equality. When $t_{\phi}=t_{\psi}$, (12) requires,

$$
\begin{aligned}
& -\alpha_{t_{\phi}}\left[P_{i t_{\phi}}^{d}-\bar{z}_{i t_{\phi}}\right]^{+}-c_{2 i}\left(\bar{z}_{i t_{\phi}}\right)^{2}+\alpha_{t_{\phi}}\left[P_{i t_{\phi}}^{d}-\bar{z}_{i t_{\phi}}-1\right]^{+} \\
& +c_{2 i}\left(\bar{z}_{i t_{\phi}}+1\right)^{2} \geq-\alpha_{t_{\phi}}\left[P_{i t_{\phi}}^{d}-\bar{z}_{i t_{\phi}}+1\right]^{+}-c_{2 i}\left(\bar{z}_{i t_{\phi}}-1\right)^{2} \\
& +\alpha_{t_{\phi}}\left[P_{i t_{\phi}}^{d}-\bar{z}_{i t_{\phi}}\right]^{+}+c_{2 i}\left(\bar{z}_{i t_{\phi}}\right)^{2}
\end{aligned}
$$

which is true for all $\alpha_{t_{\phi}} \geq 0, c_{2 i} \geq 0$ and $P_{i t_{\phi}}^{d}, \bar{z}_{i t_{\phi}} \in \mathbb{Z}$. 
Case 2: $\left|Y_{i}^{\prime \prime}\right|=\left|Y_{\psi i}^{\prime}\right|=\left|Y_{i}\right|,\left|Z_{i}^{\prime \prime}\right|+1=\left|Z_{\phi i}\right|=\left|Z_{i}\right|$. Let $Z_{i}=Z_{i}^{\prime \prime} \cup\left(l, t_{l}, p_{l}\right)$. Condition (12) requires,

$$
\begin{aligned}
& p_{i t_{l}}^{s}-\alpha_{t_{l}}\left[P_{i t_{l}}^{d}-\bar{z}_{i t_{l}}-\beta\right]^{+}-c_{2 i}\left(\bar{z}_{i t_{l}}+\beta\right)^{2}+p_{l} \\
& +\gamma_{i} t_{l} \geq-\alpha_{t_{l}}\left[P_{i t_{l}}^{d}-\bar{z}_{i t_{l}}+1-\beta\right]^{+}-c_{2 i}\left(\bar{z}_{i t_{l}}-1+\beta\right)^{2}
\end{aligned}
$$

where $\beta=1$ if $t_{l}=t_{\phi} \neq t_{\psi}$, and $\beta=0$ otherwise. This is true, since $U_{i}^{\prime}\left(Y_{i} \cup Z_{i} \cup y_{\phi} \cup z_{\psi}\right) \geq U_{i}^{\prime}\left(Y_{i} \cup Z_{i}^{\prime \prime} \cup y_{\psi} \cup z_{\phi}\right)$, and therefore contract $\left(l, t_{l}, p_{l}\right)$ provides non-negative marginal utility when selected alongside $\left\{Y_{i} \cup Z_{i}^{\prime \prime} \cup y_{\psi} \cup z_{\phi}\right\}$.

Case 3: $\left|Y_{i}^{\prime \prime}\right|+1=\left|Y_{\psi i}^{\prime}\right|=\left|Y_{i}\right|,\left|Z_{i}^{\prime \prime}\right|=\left|Z_{\phi i}\right|=\left|Z_{i}\right|$. Let $Y_{i}=Y_{i}^{\prime \prime} \cup\left(h, t_{h}, p_{h}\right)$. Condition (12) requires,

$$
\begin{aligned}
& -p_{i t_{h}}^{s}-\alpha_{t_{h}}\left[P_{i t_{h}}^{d}-\bar{z}_{i t_{h}}+\beta\right]^{+}-c_{2 i}\left(\bar{z}_{i t_{h}}-\beta\right)^{2}-c_{1 i}-p_{h} \\
& -\gamma_{i} t_{h} \geq-\alpha_{t_{h}}\left[P_{i t_{h}}^{d}-\bar{z}_{i t_{h}}-1+\beta\right]^{+}-c_{2 i}\left(\bar{z}_{i t_{h}}+1-\beta\right)^{2}
\end{aligned}
$$

where $\beta=1$ if $t_{h}=t_{\psi} \neq t_{\phi}$, and $\beta=0$ otherwise. This is true, since $U_{i}^{\prime}\left(Y_{i} \cup Z_{i} \cup y_{\psi} \cup z_{\phi}\right) \geq U_{i}^{\prime}\left(Y_{i}^{\prime \prime} \cup Z_{i} \cup y_{\psi} \cup z_{\phi}\right)$, and therefore contract $\left(h, t_{h}, p_{h}\right)$ provides non-negative marginal utility when selected alongside $\left\{Y_{i}^{\prime \prime} \cup Z_{i} \cup y_{\psi} \cup z_{\phi}\right\}$.

Case 4: $\left|Y_{i}^{\prime \prime}\right|=\left|Y_{\psi i}^{\prime}\right|=\left|Y_{i}\right|-1,\left|Z_{i}^{\prime \prime}\right|=\left|Z_{\phi i}\right|=\left|Z_{i}\right|-1$. For both $t_{\phi}=t_{\psi}$ and $t_{\phi} \neq t_{\psi}$, condition (12) results in an equality.

To show (13) is true, 5 cases need to be considered:

Case 1: $\left|Z_{i}^{\prime \prime}\right|=\left|Z_{\phi i}^{\prime}\right|=\left|Z_{\psi i}^{\prime}\right|=\left|Z_{i}\right|$. When $t_{\phi} \neq t_{\psi}$, (13) results in an equality. When $t_{\phi}=t_{\psi}$, (13) requires,

$$
\begin{aligned}
& -\alpha_{t_{\phi}}\left[P_{i t_{\phi}}^{d}-\bar{z}_{i t_{\phi}}-1\right]^{+}-c_{2 i}\left(\bar{z}_{i t_{\phi}}+1\right)^{2} \\
& +\alpha_{t_{\phi}}\left[P_{i t_{\phi}}^{d}-\bar{z}_{i t_{\phi}}-2\right]^{+}+c_{2 i}\left(\bar{z}_{i t_{\phi}}+2\right)^{2} \geq-\alpha_{t_{\phi}}\left[P_{i t_{\phi}}^{d}-\bar{z}_{i t_{\phi}}\right]^{+} \\
& -c_{2 i}\left(\bar{z}_{i t_{\phi}}\right)^{2}+\alpha_{t_{\phi}}\left[P_{i t_{\phi}}^{d}-\bar{z}_{i t_{\phi}}-1\right]^{+}+c_{2 i}\left(\bar{z}_{i t_{\phi}}+1\right)^{2}
\end{aligned}
$$

which is true for all $\alpha_{t_{\phi}} \geq 0, c_{2 i} \geq 0$ and $P_{i t_{\phi}}^{d}, \bar{z}_{i t_{\phi}} \in \mathbb{Z}$.

Case 2: $\left|Z_{\psi i}^{\prime}\right|=\left|Z_{i}\right|$ and $\left|Z_{i}^{\prime \prime}\right|=\left|Z_{\phi i}^{\prime}\right|=\left|Z_{i}\right|-1$. In this case, $t_{\phi} \neq t_{\psi}$ since $\left|Z_{\psi i}^{\prime}\right| \neq\left|Z_{\phi i}^{\prime}\right|$. Condition (13) results in an equality.

Case 3: $\left|Z_{i}^{\prime \prime}\right|=\left|Z_{\psi i}^{\prime}\right|=\left|Z_{i}\right|-1$ and $\left|Z_{\phi i}^{\prime}\right|=\left|Z_{i}\right|$. In this case, $t_{\phi} \neq t_{\psi}$ since $\left|Z_{\psi i}^{\prime}\right| \neq\left|Z_{\phi i}^{\prime}\right|$. Condition (13) results in an equality.

Case 4: $\left|Z_{\phi i}^{\prime}\right|=\left|Z_{\psi i}^{\prime}\right|=\left|Z_{i}\right|-1$ and $\left|Z_{i}^{\prime \prime}\right|=\left|Z_{i}\right|-2$. For both $t_{\phi}=t_{\psi}$ and $t_{\phi} \neq t_{\psi}$, condition (13) results in an equality.

Case 5: $\left|Z_{\phi i}^{\prime}\right|=\left|Z_{\psi i}^{\prime}\right|=\left|Z_{i}\right|$ and $\left|Z_{i}^{\prime \prime}\right|=\left|Z_{i}\right|-1$. Let $Z_{i}=Z_{i}^{\prime \prime} \cup\left(l, t_{l}, p_{l}\right)$. Condition (13) requires,

$$
\begin{aligned}
& p_{i t_{l}}^{s}-\alpha_{t_{l}}\left[P_{i t_{l}}^{d}-\bar{z}_{i t_{l}}-\beta\right]^{+}-c_{2 i}\left(\bar{z}_{i t_{l}}+\beta\right)^{2}+p_{l} \\
& +\gamma_{i} t_{l} \geq-\alpha_{t_{l}}\left[P_{i t_{l}}^{d}-\bar{z}_{i t_{l}}+1-\beta\right]^{+}-c_{2 i}\left(\bar{z}_{i t_{l}}-1+\beta\right)^{2}
\end{aligned}
$$

where $\beta=0$ if $t_{l} \neq t_{\phi}$ and $t_{l} \neq t_{\psi}$, and $\beta=1$ otherwise. This is true, since $U_{i}^{\prime}\left(Y_{i} \cup Z_{i} \cup z_{\phi}\right) \geq U_{i}^{\prime}\left(Y_{i} \cup Z_{i}^{\prime \prime} \cup z_{\phi}\right)$ and $U_{i}^{\prime}\left(Y_{i} \cup Z_{i} \cup z_{\psi}\right) \geq U_{i}^{\prime}\left(Y_{i} \cup Z_{i}^{\prime \prime} \cup z_{\psi}\right)$, and therefore contract $\left(l, t_{l}, p_{l}\right)$ provides non-negative marginal utility when selected alongside either $\left\{Y_{i} \cup Z_{i}^{\prime \prime} \cup z_{\phi}\right\}$ or $\left\{Y_{i} \cup Z_{i}^{\prime \prime} \cup z_{\psi}\right\}$.

\section{REFERENCES}

[1] J. Guerrero, F. Blaabjerg, T. Zhelev, K. Hemmes, E. Monmasson, S. Jemeï, M. P. Comech, R. Granadino, and J. I. Frau, "Distributed Generation: Toward a New Energy Paradigm," IEEE Industrial Electronics Magazine, vol. 4, no. 1, pp. 52-64, 2010.

[2] Y. Parag and B. K. Sovacool, "Electricity Market Design for the Prosumer Era," Nature Energy, vol. 1, no. 4, pp. 1-6, 2016.
[3] R. Wilson, "Architecture of Power Markets," Econometrica, vol. 70, no. 4, pp. 1299-1340, 2002.

[4] D. Wu, M. Kintner-Meyer, Tao Yang, and P. Balducci, "Economic Analysis and Optimal Sizing for Behind-the-Meter Battery Storage," IEEE Power and Energy Society General Meeting, pp. 1-5, 2016.

[5] L. N. Ochoa, F. Pilo, A. Keane, P. Cuffe, and G. Pisano, "Embracing an Adaptable, Flexible Posture: Ensuring That Future European Distribution Networks Are Ready for More Active Roles," IEEE Power and Energy Magazine, vol. 14, no. 5, pp. 16-28, 2016.

[6] D. Pudjianto, C. K. Gan, V. Stanojevic, M. Aunedi, P. Djapic, and G. Strbac, "Value of Integrating Distributed Energy Resources in the UK Electricity System," IEEE Power and Energy Society General Meeting, pp. 1-6, 2010.

[7] R. Li, Q. Wu, and S. S. Oren, "Distribution Locational Marginal Pricing for Optimal Electric Vehicle Charging Management," IEEE Transactions on Power Systems, vol. 29, no. 1, pp. 203-211, 2014.

[8] S. S. Guggilam, E. Dall'Anese, Y. C. Chen, S. V. Dhople, and G. B. Giannakis, "Scalable Optimization Methods for Distribution Networks with High PV Integration," IEEE Transactions on Smart Grid, vol. 7, no. 4, pp. 2061-2070, 2016.

[9] T. Morstyn, A. V. Savkin, B. Hredzak, and H. D. Tuan, "Scalable Energy Management for Low Voltage Microgrids Using Multi-Agent Storage System Aggregation," IEEE Transactions on Power Systems, vol. PP, no. $99,2017$.

[10] T. Morstyn, B. Hredzak, R. P. Aguilera, and V. G. Agelidis, "Model Predictive Control for Distributed Microgrid Battery Energy Storage Systems," IEEE Transactions on Control Systems Technology, vol. PP, no. $99,2017$.

[11] N. Good, K. A. Ellis, and P. Mancarella, "Review and Classification of Barriers and Enablers of Demand Response in the Smart Grid," Renewable and Sustainable Energy Reviews, vol. 72, pp. 57-72, 2017.

[12] GridWise Architecture Council, "GridWise Transactive Energy Framework Version 1.0," pp. 1-43, 2013.

[13] P. Grünewald, E. McKenna, and M. Thomson, "Keep it Simple: Time-ofUse Tariffs in High-Wind Scenarios," IET Renewable Power Generation, vol. 9, no. 2, pp. 176-183, 2015.

[14] K. Heussen, S. You, B. Biegel, L. H. Hansen, and K. B. Andersen, "Indirect Control for Demand Side Management - A Conceptual Introduction," IEEE Innovative Smart Grid Technologies Conference Europe, pp. 1-7, 2012.

[15] D. Papadaskalopoulos and G. Strbac, "Decentralized Participation of Flexible Demand in Electricity Markets - Part I: Market Mechanism," IEEE Transactions on Power Systems, vol. 28, no. 4, pp. 3658-3666, 2013.

[16] M. Karlsson, F. Ygge, and A. Andersson, "Market-Based Approaches to Optimization," Computational Intelligence, vol. 23, no. 1, pp. 92-109, 2007.

[17] M. Kraning, E. Chu, J. Lavaei, and S. Boyd, "Dynamic Network Energy Management via Proximal Message Passing," Foundations and Trends in Optimization, vol. 1, no. 2, pp. 70-122, 2014.

[18] F. Moret and P. Pinson, "Energy Collectives: A Community and Fairness Based Approach to Future Electricity Markets," IEEE Transactions on Power Systems, vol. PP, no. 99, 2018.

[19] T. Morstyn and M. McCulloch, "Multi-Class Energy Management for Peer-to-Peer Energy Trading Driven by Prosumer Preferences," IEEE Transactions on Power Systems, no. 99, 2018.

[20] E. Munsing, J. Mather, and S. Moura, "Blockchains for Decentralized Optimization of Energy Resources in Microgrid Networks," IEEE Conference on Control Technology and Applications (CCTA), pp. 21642171, 2017.

[21] J. Lee, J. Guo, J. K. Choi, and M. Zukerman, "Distributed Energy Trading in Microgrids: A Game Theoretic Model and Its Equilibrium Analysis," IEEE Transactions on Industrial Electronics, vol. 62, no. 6, pp. 3524-3533, 2015.

[22] M. Khorasany, Y. Mishra, and G. Ledwich, "Auction Based Energy Trading in Transactive Energy Market with Active Participation of Prosumers and Consumers," Australasian Universities Power Engineering Conference (AUPEC), pp. 1-6, 2017.

[23] M. N. Faqiry and S. Das, "Double-Sided Energy Auction in Microgrid: Equilibrium Under Price Anticipation," IEEE Access, vol. 4, pp. 3794 $3805,2016$.

[24] J. Guerrero, A. Chapman, and G. Verbic, "A Study of Energy Trading in a Low-Voltage Network: Centralised and Distributed Approaches," in Australasian Universities Power Engineering Conference (AUPEC), 2017, pp. 1-6. 
[25] Z. Ma, D. S. Callaway, and I. A. Hiskens, "Decentralized Charging Control of Large Populations of Plug-in Electric Vehicles," IEEE Transactions on Control Systems Technology, vol. 21, no. 1, 2013.

[26] L. Deori, K. Margellos, and M. Prandini, "On the Connection Between Nash equilibria and Social Optima in Electric Vehicle Charging Control Games," 20th World Congress of the International Federation of Automatic Control, pp. 1-6, 2016.

[27] A. De Paola, D. Angeli, and G. Strbac, "Price-Based Schemes for Distributed Coordination of Flexible Demand in the Electricity Market," IEEE Transactions on Smart Grid, vol. 8, no. 6, pp. 3104-3116, 2017.

[28] W. Wei, F. Liu, and S. Mei, "Energy Pricing and Dispatch for Smart Grid Retailers Under Demand Response and Market Price Uncertainty,' IEEE Transactions on Smart Grid, vol. 6, no. 3, pp. 1364-1374, 2015.

[29] S. D. Manshadi and M. E. Khodayar, "A Hierarchical Electricity Market Structure for the Smart Grid Paradigm," IEEE Transactions on Smart Grid, vol. 7, no. 4, pp. 1866-1875, 2016.

[30] L. Jia and L. Tong, "Renewables and Storage in Distribution Systems: Centralized vs. Decentralized Integration," IEEE Journal on Selected Areas in Communications, vol. 34, no. 3, pp. 665-674, 2016.

[31] N. Liu, X. Yu, C. Wang, C. Li, L. Ma, and J. Lei, “An Energy Sharing Model with Price-based Demand Response for Microgrids of Peer-toPeer Prosumers," IEEE Transactions on Power Systems, vol. PP, no. 99, 2017.

[32] A. R. Soares, O. D. Somer, D. Ectors, F. Aben, J. Goyvaerts, M. Broekmans, F. Spiessens, D. van Goch, and K. Vanthournout, "Distributed Optimization Algorithm for Residential Flexibility Activation - Results from a Field Test," IEEE Transactions on Power Systems, vol. PP, no. 99, 2018.

[33] K. Kok, B. Roossien, P. Macdougall, and O. V. Pruissen, "Dynamic Pricing by Scalable Energy Management Systems - Field Experiences and Simulation Results using PowerMatcher," IEEE Power and Energy Society General Meeting, pp. 1-8, 2012.

[34] P. L. Joskow, "Why Do We Need Electricity Retailers?; Or, Can You Get it Cheaper Wholesale?" Centre for Energy and Environmental Policy Research, pp. 1-57, 2000.

[35] D. T. Nguyen, M. Negnevitsky, and M. de Groot, "Pool-Based Demand Response Exchange-Concept and Modeling," IEEE Transactions on Power Systems, vol. 26, no. 3, pp. 1677-1685, 2011.

[36] K. Heussen, D. E. M. Bondy, J. Hu, O. Gehrke, and L. H. Hansen, "A Clearinghouse Concept for Distribution-Level Flexibility Services," IEEE Innovative Smart Grid Technologies Europe, pp. 1-5, 2013.

[37] C. Zhang, Y. Ding, N. C. Nordentoft, P. Pinson, and J. Østergaard, "FLECH: A Danish Market Solution for DSO Congestion Management Through DER Flexibility Services," Journal of Modern Power Systems and Clean Energy, vol. 2, no. 2, pp. 126-133, 2014.

[38] S. S. Torbaghan, N. Blaauwbroek, P. Nguyen, and M. Gibescu, "Local Market Framework for Exploiting Flexibility from the End Users," International Conference on the European Energy Market, EEM, pp. 1-6, 2016.

[39] T. Morstyn, A. Teytelboym, and M. D. McCulloch, "Bilateral Contract Networks for Peer-to-Peer Energy Trading," IEEE Transactions on Smart Grid, vol. PP, no. 99, 2018.

[40] E. Sorin, L. Bobo, and P. Pinson, "Consensus-Based Approach to Peer-to-Peer Electricity Markets with Product Differentiation," IEEE Transactions on Power Systems, vol. PP, no. 99, 2018.

[41] E. Mengelkamp, J. Gärttner, K. Rock, S. Kessler, L. Orsini, and C. Weinhardt, "Designing Microgrid Energy Markets. A Case Study: The Brooklyn Microgrid," Applied Energy, vol. 210, pp. 870-880, 2017.

[42] T. Morstyn, N. Farrell, S. J. Darby, and M. D. McCulloch, "Using Peer-to-Peer Energy-Trading Platforms to Incentivize Prosumers to Form Federated Power Plants," Nature Energy, vol. 3, no. 2, pp. 94-101, 2018.

[43] J. Villar, R. Bessa, and M. Matos, "Flexibility Products and Markets: Literature Review," Electric Power Systems Research, vol. 154, pp. 329 $340,2018$.

[44] H. Shareef, M. S. Ahmed, A. Mohamed, and E. Al Hassan, "Review on Home Energy Management System Considering Demand Responses, Smart Technologies, and Intelligent Controllers," IEEE Access, vol. 6, pp. 24 498-24 509, 2018.

[45] J. Ossenbrink, "How Feed-In Remuneration Design Shapes Residential PV Prosumer Paradigms," Energy Policy, vol. 108, pp. 239-255, 2017.

[46] W. Charytoniuk, M. Chen, P. Kotas, and P. Van Olinda, "Demand Forecasting in Power Distribution Systems Using Nonparametric Probability Density Estimation," IEEE Transactions on Power Systems, vol. 14, no. 4, pp. 1200-1206, 1999.

[47] S. Villalba and C. Bel, "Hybrid Demand Model for Load Estimation and Short Term Load Forecasting in Distribution Electric Systems," IEEE Transactions on Power Delivery, vol. 15, no. 2, pp. 764-769, 2000.
[48] O. Mégel, J. L. Mathieu, and G. Andersson, "Scheduling Distributed Energy Storage Units to Provide Multiple Services," Power Systems Computation Conference (PSCC), pp. 1-7, 2014.

[49] W. El-Baz and P. Tzscheutschler, "Short-Term Smart Learning Electrical Load Prediction Algorithm for Home Energy Management Systems," Applied Energy, vol. 147, pp. 10-19, 2015.

[50] N. Liu, M. Cheng, X. Yu, J. Zhong, and J. Lei, "Energy Sharing Provider for PV Prosumer Clusters: A Hybrid Approach Using Stochastic Programming and Stackelberg Game," IEEE Transactions on Industrial Electronics, vol. 65, no. 8, pp. 6740-6750, 2018.

[51] A. E. Roth, "What Have We Learned from Market Design? (Update)," Economic Journal, vol. 118, no. 2006, pp. 285-310, 2008.

[52] J. W. Hatfield, S. D. Kominers, A. Nichifor, M. Ostrovsky, and A. Westkamp, "Stability and Competitive Equilibrium in Trading Networks," Journal of Political Economy, vol. 121, no. 5, pp. 966-1005, 2013.

[53] T. Fleiner, R. Jagadeesan, Z. Jankó, and A. Teytelboym, "Trading Networks with Frictions," in Proceedings of the ACM Conference on Economics and Computation, 2018, pp. 615-615.

[54] T. Fleiner, Z. Jankó, A. Tamura, and A. Teytelboym, "Trading Networks with Bilateral Contracts," in The Third Conference on Auctions, Market Mechanisms and Their Applications, 2015, pp. 1-39.

[55] J. W. Hatfield, S. D. Kominers, A. Nichifor, M. Ostrovsky, and A. Westkamp, "Full Substitutability in Trading Networks," in Sixteenth ACM Conference on Economics and Computation, 2015, pp. 39-40.

[56] European Low Voltage Test Feeder, "IEEE PES Distribution Systems Analysis Subcommittee Test Feeders." [Online]. Available: ewh.ieee.org/soc/pes/dsacom/testfeeders/

[57] R. Cespedes, "New Method for the Analysis of Distribution Networks," IEEE Transactions on Power Delivery, vol. 5, no. 1, pp. 391-396, 1990.

[58] Customer-Led Network Revolution, "Enhanced Profiling of Domestic Customers With Solar Photovoltaics." [Online]. Available: networkrevolution.co.uk

[59] M. Muratori, "Impact of Uncoordinated Plug-In Electric Vehicle Charging on Residential Power Demand - Supplementary Data," National Renewable Energy Laboratory, 2017. [Online]. Available: data.nrel.gov/submissions/69

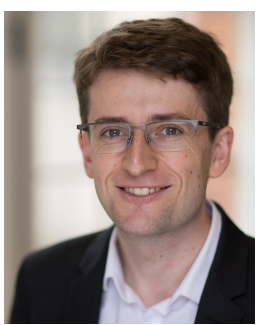

Thomas Morstyn (S'14-M'16) received the B.E. (Hon.) degree from the University of Melbourne, Australia, in 2011, and the PhD degree from the University of New South Wales, Australia, in 2016 , both in electrical engineering.

He worked as an electrical engineer in the Rio Tinto Technology and Innovation group between 2012 and 2014. He is currently an EPSRC Research Fellow with the Department of Engineering Science at the University of Oxford. His research interests include multi-agent control and market design for integrating distributed energy resources in power systems.

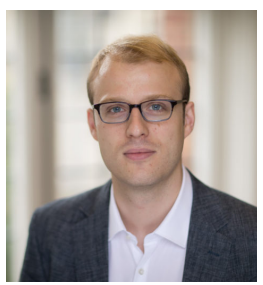

Alexander Teytelboym received a B.Sc. in Economics (2008) from the L.S.E. and M.Phil. (2010) and D.Phil. in Economics (2013) from the University of Oxford.

$\mathrm{He}$ is an economist interested in market design as well as social and economic networks. Before joining the Department of Economics, he was the Otto Poon Research Fellow at the Institute for New Economic Thinking at the Oxford Martin School and prior to that a Postdoctoral Fellow at the Laboratory for Information and Decision Systems at M.I.T.

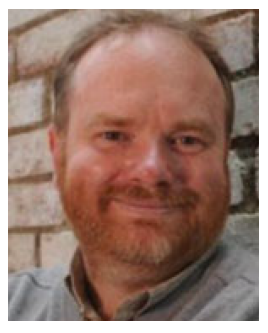

Malcolm D. McCulloch (SM'89) received the B.Sc. (Eng.) and Ph.D. degrees in electrical engineering from the University of the Witwatersrand, Johannesburg, South Africa, in 1986 and 1990, respectively.

In 1993, he joined the University of Oxford, Oxford, U.K., to head up the Energy and Power Group, where he is currently an Associate Professor in the Department of Engineering Science. He is active in the areas of electrical machines, transport, and smart grids. His work addresses transforming existing power networks, designing new power networks for the developing world, developing new technology for electric vehicles, and developing approaches to integrated mobility. 